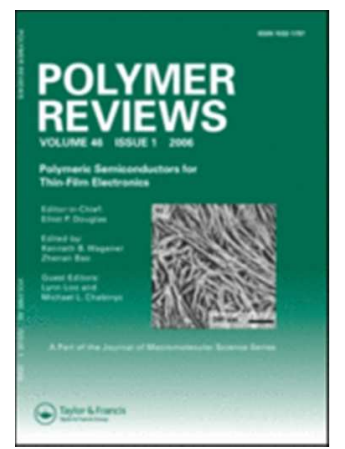

\title{
From vegetable oils to polyurethanes: synthetic routes to polyols and main industrial products
}

\begin{tabular}{|r|l|}
\hline Journal: & Polymer Reviews \\
\hline Manuscript ID: & LMSC-2011-0133.R1 \\
\hline Manuscript Type: & Review \\
\hline Date Submitted by the Author: & n/a \\
\hline Complete List of Authors: & $\begin{array}{l}\text { Desroches, Myriam; ICGM } \\
\text { Escouvois, Maxime; ICGM } \\
\text { Auvergne, Remi; ICGM } \\
\text { CAILLOL, Sylvain; ICGM, IAM } \\
\text { Boutevin, Bernard; ICGM }\end{array}$ \\
\hline Keywords: & $\begin{array}{l}\text { vegetable oils, biobased polyols, polyurethanes, epoxidized vegetable oils, } \\
\text { commercial polyols }\end{array}$ \\
\hline
\end{tabular}

\section{SCHOLARONE}

Manuscripts 


\section{From vegetable oils to polyurethanes: synthetic routes to polyols and main industrial products}

Myriam Desroches, Maxime Escouvois, Remi Auvergne, Sylvain Caillol*, Bernard Boutevin

Institut Charles Gerhardt Montpellier, UMR 5253 CNRS-UM2-ENSCM-UM1, Equipe I.A.M., 8 Rue de l'Ecole Normale, 34296 Montpellier Cedex 5, France

*Corresponding author. Dr Sylvain CAILLOL. Address: ENSCM, 8 Rue de 1'Ecole Normale, 34296 Montpellier Cedex 5, France - E-mail sylvain.caillol@enscm.fr.

Short title : From research to industrial biobased polyols 


\title{
From vegetable oils to polyurethanes: synthetic routes to polyols and main industrial products
}

\begin{abstract}
Most of biobased polyols for polyurethanes are synthesized from vegetable oils. In a first part, the present review goes into details of these different synthetic routes to obtain polyols. Firstly, olefinic functionalities of triglycerides could easily be epoxidized, leading to reactive epoxide groups. Secondly, triglycerides double bonds could undergo a wide range of reaction to yield polyols. Finally, the carbonyl group could also be used as a reactive group to yield various polyols. In a second part, the present review is dedicated to the commercial biobased polyols, and, based on the patent literature; focus on the industrial synthetic routes.
\end{abstract}

Keywords: vegetable oils; biobased polyols; polyurethanes; epoxidized vegetable oils; commercial polyols; oxidation

\section{Introduction}

Uncertainty in terms of price and availability of petroleum, in addition to global political and institutional tendencies toward the principles of sustainable development, urge chemical industry to a sustainable chemistry and particularly the use of renewable resources in order to synthesize biobased chemicals and products. A biobased product is a product synthesized from renewable resources (vegetal, animal or fungal) but doesn't mean that it is a biodegradable material. Biodegradability is a special functionality conferred to a material, biobased or not, and biobased sourcing does not entail biodegradability. Biobased sourcing could be measured by renewable carbon content owing to D6866ASTM standards. The use of renewable resources for chemical synthesis results in reduction of environmental impacts such as non-renewable resources consumptions and greenhouse gas emission. But hazards of chemicals should also be taken into account in order to reduce human toxicity and eco-toxicity impacts. Indeed, it is not sufficient to synthesize exactly the same chemicals from renewable 
resources, even if they are harmful. Biobased chemicals could also be very dangerous. New processes have to be developed to replace hazardous reactives by harmless, biobased ones. Among this new developments, we report some polyamides, such as polyamide 11 synthesized from castor oil by Arkema Group under the brand name Rilsan ${ }^{1}$, biofuels and polyols. Polyols represent increasing industrial developments in various applications and particularly in polyurethanes.

Polyurethanes (PUs), having a relatively short history, of slightly more than 70 years, became one of the most dynamic groups of polymers, exhibiting versatile properties suitable for use in practically all the fields of polymer applications - foams, elastomers, thermoplastics, thermorigids, adhesives, coatings, sealants, fibers and so on. With a global production of $14 \mathrm{Mt}$ in 2006 , PUs are the 6 th most widely used polymer ${ }^{2}$. Additionally, they are used in some specialty applications such as biomedical surgery. PUs are obtained by the reaction of an oligomeric polyol (low molecular weight polymer with terminal hydroxyl groups) and a diisocyanate (or polyisocyanate) (Scheme 1). All these raw materials come from petroleum but recently, chemical industry has paid intensive interest to the production of biobased polyols, mainly synthesized from vegetable oils ${ }^{3-5}$.

Insert Scheme 1: Polyurethane synthesis from diol and diisocyanate

Indeed, most of polyols currently used for polyurethanes synthesis are polyether polyols $(75 \%)$, resulting from the reaction between a "starter" polyol and an alkylene oxide, both petrobased. Other polyols used for polyurethanes synthesis are polyesters polyols $(25 \%)$, obtained by step growth polycondensation between dicarboxylic acid and polyol in excess ${ }^{6}$. A first approach to increase the renewable content of polyurethanes consists in replacing the "starter" polyol by a biobased polyol from saccharides (sorbitol, sucrose) for the synthesis of partially biobased polyether polyols 
(30\% renewable carbon). However, it results in low renewable content polyurethanes (around 8\%). Therefore it is more interesting to work on prepolymers that account for higher percentage of renewable content. Polyether polyol could also be obtained by polycondensation of propane-1,3-diol coming from glycerin. Furthermore, biobased polyester polyols generally result from condensation of biobased dicarboxylic acids such as adipic or succinic acid with biobased polyols (propane-1,3-diol).

Finally, another approach to obtain biobased polyols consists in the use of natural oils (vegetable or animal) i.e. the most abundant and cheapest renewable organic resources ${ }^{7}$.

Insert Scheme 2: Triglyceride formula with R0, R1 and R3 aliphatic chains of fatty acids

Vegetable oils are coming from various plants (soybean, palm, rapeseed...) and contain mainly triglycerides molecules where the three hydroxyl functions of glycerin are esterified with fatty acids (Scheme 2). These fatty acids could be saturated - with non reactive aliphatic chains (stearic or palmitic acids...) or unsaturated - with aliphatic chains bearing double bonds (oleic, linoleic, linolenic, ricinoleic acids...). These natural oils, and particularly unsaturated ones, are very interesting since various reactions could be performed from their different groups in order to obtain biobased polyols, enabling reactions with diisocyanates to get polyurethanes.

Fundamental research has investigated vegetable oils functionalization for several years and several reviews were published ${ }^{7-19}$. However, none of these review report so far current industrial applications of depicted methods, patented processes and synthesized biobased polyols. Therefore general presentation of vegetable oil functionalization reaction is reported in part $\mathrm{A}$ of this review, whereas the industrial state of the art of industrial processes and products is reported in part B. 


\section{Part A: synthetic routes from vegetable oils to polyols}

Chemistry routes followed to functionalize vegetable oils are extremely various and are based on several reactions. In order to summarize these routes, we reported the main reactions discussed in this review (Table 1).

Insert Table 1: Mains reactions used on vegetable oils

In order to facilitate reading reaction schemes reported in this review, triglycerides were presented owing to formula of Scheme 3 , with aliphatic chain $R_{0}$ corresponding to oleic acid (one double bond between carbons 9 and 10). $R_{1}$ and $R_{2}$ chains could correspond to a fatty acid mono- or poly- unsaturated or non saturated.

Insert Scheme 3: Triglyceride formula with $\mathrm{R}_{0}$ chain corresponding to oleic acid

\section{Routes from epoxidized vegetable oils}

Epoxidized soybean oil could be used in addition to other commercial polyols in polyurethanes formulation ${ }^{20}$. Epoxide group are particularly interesting since after nucleophilic attack, they lead to various molecules owing to the nature of nucleophiles. The first route reported to functionalize triglycerides processes in two steps : epoxidation of double bonds of unsaturated fatty acids (reaction A, Table 1) followed by nucleophilic ring opening of epoxide group (reaction B, Table 1). Thus one or more alcohol functions (owing to nucleophiles) can be added onto the fatty acid aliphatic chain.

\section{I.1. Double bonds epoxidation}

Vegetable oils can be epoxidized (reaction A, Table 1), leading to interesting building blocks for biobased chemistry ${ }^{21}$. The most currently used method to epoxidize vegetable oil is based on peracetic acid formed in situ from reaction between acetic acid 
and hydrogen peroxide, with ion-exchange resin catalyst, at $60^{\circ} \mathrm{C}$ in toluene, during $12 \mathrm{~h}$ (Scheme 4). Double bond conversion into epoxide functions can be quantitative ${ }^{22}$. Vegetable oils can also be epoxidized by micro-waves. This interesting process leads to yields higher than $90 \%$ within $5 \mathrm{mn}{ }^{23}$. Enzymatic epoxidation of vegetable oils were also reported ${ }^{24-26}$ but is not detailed in this review.

Insert Scheme 4: Synthesis of epoxidized triglycerides

\section{I.2. Epoxide ring opening in situ}

Epoxide ring opening can be performed in situ, by sulfuric acid and water at $65^{\circ} \mathrm{C}$ (Scheme 5). In a first step, double bonds are epoxidized (reaction A, Table 1), then epoxide groups are converted in vicinal secondary alcohol ${ }^{27-29}$ (reaction B, Table 1 where $\mathrm{NuH}$ is water). This simple method yields hydroxylated vegetable oil ${ }^{30-35}$. A method wit organometallic catalyst was also reported ${ }^{36}$.

Insert Scheme 5: In situ triglyceride epoxide ring opening

\section{I.3. Conversion of epoxide groups by monofunctional reagents}

Alcoholysis of epoxidized vegetable oils with mono-alcohol and an acid catalyst also leads to polyols with secondary alcohols (reaction B, Table 1 where $\mathrm{NuH}$ is a mono-alcohol). Methanol is often used (Scheme 6), at refluxing temperature, with concentrated sulfuric acid ${ }^{37-39}$ or p-toluenesulfonic acid ${ }^{40}$ as catalyst. Following the same protocol, other alcohols, such as 2-Ethyl-1-hexanol, are used ${ }^{41,42}$.

Insert Scheme 6: Triglycerides epoxide ring opening by methanol

For recent years, the most used epoxide ring opening reaction consists in a reaction with methanol (or other mono-alcohol), in water, with fluoroboric acid catalyst (Scheme 6). After heating $30 \mathrm{~min}$ between 50 and $65^{\circ} \mathrm{C}$ (refluxing temperature for methanol) 
reaction yield reaches around $80 \% 4,22,43-48$. The obtained polyester polyol could thus react with diisocyanates to lead to polyurethanes, particularly in aqueous cationic dispersion for polyurethane films casting with interesting stretching properties ${ }^{49}$.

The epoxidation of triolein after metathesis reaction (reaction $\mathrm{M}$, Table 1) is an interesting example. Epoxide groups are ring opened by methanol in presence of fluoroboric acid. This three steps reaction leads to terminal hydroxyl groups that could react with diisocyanates to yield polyurethanes with short dangling chains ${ }^{22}$ (Scheme 7).

Insert Scheme 7: Synthesis of primary terminal alcohols from triolein for polyurethanes formulation

The use of heterogeneous catalysts was reported for alcoholysis of epoxidized vegetable oils, such as activated clay ${ }^{50}$ or ion-exchange resins ${ }^{51}$.

Epoxide ring opening polymerization of epoxidized methyl oleate was also reported in presence of $\mathrm{HSbF}_{6}$. Polymerization is followed by partial reduction of esters (Scheme 8), yielding to alcohol functions ${ }^{52}$. This original method allows obtaining polyether polyols with interesting functionality comprised between 2 and 5 for polyurethane formulation.

Insert Scheme 8: Epoxide ring opening polymerization of epoxidized methyl oleate

Another method used a thiol as nucleophile instead of alcohol ${ }^{53-55}$ (reaction B, Table 1). Thus reaction of triglycerides with butane-1-thiol was reported at $45^{\circ} \mathrm{C}$, during 1h under nitrogen with perchloric acid catalyst (Scheme 9) ${ }^{54}$.

Insert Scheme 9: Triglyceride epoxide ring opening with butane-1-thiol

A secondary amine could also be used as nucleophile (reaction B, Table 1). Thus, diethylamine was used for epoxide ring opening of triglycerides with zinc 
chloride, at $80^{\circ} \mathrm{C}$, during $4 \mathrm{~h}{ }^{56}$ (Scheme 10 ). In this study, choice of amine, catalyst and synthesis parameters were optimized in order to favour epoxide ring opening reaction instead of amide formation (reaction $\mathrm{J}$, Table 1). Indeed, reaction of amines with triglycerides esters may compete epoxide ring opening.

Insert Scheme 10 : Oxirane ring opening with diethylamine

Reactions with halogen reagents such as $\mathrm{HCl}$ or $\mathrm{HBr}$ were also reported ${ }^{57-60}$. Brominated and chlorinated polyols exhibit higher densities and viscosities than the methoxylated or hydrogenated ones. Epoxide ring opening could also be performed by reaction with carboxylic acid (reaction $\mathrm{B}$, Table 1 ), such as fatty acid ${ }^{61}$, acetic acid ${ }^{62}$, cinnamic acid ${ }^{63}$, acrylic acid ${ }^{64}$ (Scheme 11), lactic acid ${ }^{5}$, levulinic acid ${ }^{65}$ or anhydrides 33,66 . These reactions lead to saturated polyester polyols with improved resistance towards oxidation and interesting antiwear properties for lubricating applications. Similarly, epoxided fatty ester react with carboxylic acid to yield stearates with hydroxyl and ester functions on both $9^{\text {th }}$ or $10^{\text {th }}$ carbons of aliphatic chain ${ }^{67}$. Propionic, levulinic, hexanoic or octanoic are the most currently used carboxylic acids 67-69.

Insert Scheme 11 : Triglyceride epoxide ring opening with acrylic acid

\section{I.4. Hydrogenation of epoxide groups}

Epoxide groups can also be directly hydrogenated (reaction $\mathrm{C}$, Table 1) from dihydrogene addition with Raney nickel catalyst (Scheme 12). In that case, the obtained triglycerides exhibit only secondary hydroxyl functions ${ }^{57,58,70}$.

Insert Scheme 12: Direct hydrogenation of triglyceride epoxides

Triglycerides with secondary hydroxyl functions were used for polyurethane

synthesis ${ }^{3}$. However, considering the higher reactivity of primary alcohols towards 
isocyanates, it is more interesting to functionalize triglycerides with polyfunctional reactants in order to insert primary hydroxyl functions on triglycerides chains.

\section{I.5. Conversion of epoxide groups by polyfunctional reagents}

Diol could be used as nucleophile for epoxide ring opening in order to insert at least both primary and secondary hydroxyl functions on each epoxide group of triglyceride (reaction B). Literature reports the reaction with ethan-1,2-diol (Scheme 13). This reaction is performed with concentrated sulfuric acid at $100^{\circ} \mathrm{C}{ }^{38,} 71$, with tetrafluoroboric acid at $50^{\circ} \mathrm{C}$ to $95^{\circ} \mathrm{C}$ in $2 \mathrm{~h}{ }^{72-74}$ or with a diethylether-trifuoride borate complex between $60^{\circ} \mathrm{C}$ and $100^{\circ} \mathrm{C}^{75}$.

Insert Scheme 13: Triglyceride epoxide ring opening by ethan-1,2-diol

Various polyols were also described in order to insert three or more hydroxyl functions per epoxide group with two or more primary hydroxyl functions ${ }^{76}$. Reactions were reported with diethanolamine $\left(2,2^{\prime}\right.$-iminodiethanol), or triethanolamine $\left(2,2^{\prime}, 2^{\prime \prime}\right.$ nitrilotriethanol), with sulfuric acid at $200^{\circ} \mathrm{C}$ during $2-4 \mathrm{~h}$, or with $\mathrm{LiOH}$ catalyst at $150^{\circ} \mathrm{C}^{77}$. However, several issues are raised when using polyfunctional molecules ${ }^{78}$ :

- A side-reaction of oligomerization occurs between triglycerides bearing primary hydroxyl functions and epoxided triglycerides. This oligomerization is favored by high catalyst concentration and low alcohol concentration;

- Side reactions involving ester groups of triglycerides (reaction I, J, Table 1) are competitive to epoxide ring opening reactions.

The use of different temperatures (ranging from $110^{\circ} \mathrm{C}$ to $180^{\circ} \mathrm{C}$ ) as well as different reaction times (ranging from 5 to $7 \mathrm{~h}$ ) lead to various mixtures of fatty amide polyols and glycerin, resulting from the amidification reaction, and amine diols, obtained from oxirane ring opening reation (Scheme 14). It was demonstrated that 
epoxide ring opening by diethanolamine is favored by using both high temperature $\left(\sim 180^{\circ} \mathrm{C}\right)$ and long reaction time $(\sim 7 \mathrm{~h})^{79}$.

Insert Scheme 14: Competitive reactions occurring during triglyceride amidification by diethanolamine

A patent ${ }^{80}$ reports a two steps process to synthesize polyols from vegetable oils. In a first step, vegetable oil is epoxided by $\mathrm{H}_{2} \mathrm{O}_{2}$ in acidic conditions. In a second step, epoxide ring opening occurs with polyols or alcoholamines. More than $80 \%$ of epoxide groups are converted into primary or secondary hydroxyl functions. The obtained product is a mix of polyesters and polyether polyols, resulting from partial transesterification of triglycerides (reaction I, Table 1) and epoxide ring opening (reaction B, Table 1), respectively.

Alcanolamides were also synthesized directly from laurel oil (45\% of saturated fatty acids) by reaction with ethanolamine (2-aminoethanol) at room temperature with sodium methoxide catalyst ${ }^{81}$. The same catalyst was used to synthesize diethanolamides from hydroxyl methyl oleate ${ }^{82}$. Polyols polyamines were also synthesized from epoxidized vegetable oils by reaction with a mixture of amines or alcoholamines at temperatures between $100^{\circ} \mathrm{C}$ and $200^{\circ} \mathrm{C}$. Glycerin co-produced was distillated and epoxidized fatty amides were obtained ${ }^{79,83,84}$. These products were reacted with diisocyananes to yield crosslinked polyurethanes.

A study reports the synthesis of polyols from tallow by reaction with trimethylolpropane (2-(hydroxymethyl)-2-ethylpropane-1,3-diol) in the presence of acid or basic catalyst ${ }^{85}$. Oxirane ring opening by polyol is favored by an acid catalyst such as p-toluenesulfonic acid (reaction B, Table 1), whereas a basic catalyst such as sodium methoxide favors transesterification of ester group (reaction I, Table 1). 
Finally, an hydroxyl-acid such as lactic acid (Scheme 15) is also able to graft hydroxyl groups onto epoxidized vegetable oils. The reaction was performed at $90^{\circ} \mathrm{C}$ under nitrogen during $6 \mathrm{~h}$, leading to an epoxide conversion around $70 \% 5$.

Insert Scheme 15: Triglyceride epoxide ring opening with lactic acid

Finally, epoxide ring opening by difunctional nucleophile yields polyols with higher functionality. Polyols systematically exhibit secondary hydroxyl groups and may also bear primary hydroxyl groups from extra function of nucleophile.

\section{I.6. Epoxide groups carbonatation}

Direct carbonatation of epoxidized soybean oil was also reported (reaction O, Table 1) ${ }^{86-88}$. In a second step, polyols are synthesized by ring opening with ethanolamine (Scheme 16).

Insert Scheme 16: Polyols synthesis from carbonated oil

It is to be noted that this reaction leads to carbonated oils that are able to react with polyamines to give interesting nonisocyanate polyurethanes ${ }^{89,} 90$. The different methods to functionalize epoxidized vegetable oils are given in Scheme 17.

Insert Scheme 17: Summary of most common functionalizations on epoxidized vegetable oils

\section{Double bonds oxidation to alcohols}

The synthesis of polyols from vegetable oils could also be carried out directly by oxidation of double bonds. Various reactions of direct oxidation reaction are reported.

\section{II.1. Ozonolysis-hydrogenation process}

Oxidative cleavage of a double bond by ozone (reaction D, Table 1) leads to aldehyde group ${ }^{91}$. Therefore, the application of this reaction to an unsaturated vegetable oil yields a maximum of three aldehyde functions per triglyceride molecule (one terminal 
aldehyde on each fatty acid chain). A following reaction of reduction of aldehyde functions into primary alcohols leads to a polyol with a maximum of three hydroxyl functions (reaction $\mathrm{H}$, Table 1).

Ozonolysis was performed on soybean oil, rapeseed oil or synthetic triglycerides yielded polyols with primary hydroxyl groups (Scheme 18). Oxidative cleavage of oleic acid by ozone into azelaic (nonanedioic) and pelargonic (nonanoic) acids is the most important industrial application of ozonolysis ${ }^{25}$.

Insert Scheme 18: Ozonolysis of unsaturated triglycerides leading to terminal primary hydroxyl functions

Several ozonolysis methods were reported. Ozonolysis could be performed in a mixture of solvents such as methanol and dichloromethane, with sodium borohydride ${ }^{92}$, 93. Another method reports ozonolysis in water, followed by hydrogenation in tetrahydrofuran with Raney nickel ${ }^{94}$. The reaction in ethyl acetate with zinc powder yielded polyols with highest hydroxyl functionality ${ }^{95}$. The ozonolysis with $\mathrm{CaCO}_{3}$ was also reported on soybean oil in the presence of ethylene glycol. The diol was added to terminal carbons through an ester covalent bond, leading to a mixture of polyester polyols ${ }^{91}$.

\section{II.2. Double bonds oxidation into peroxides and reduction into alcohols}

Air oxidation of unsaturated vegetable oils leads to triglycerides with hydroxyl functions and double bonds ${ }^{96-98}$. Oxidation may also yield vegetable oil derivatives with enone groups ${ }^{18}$ (Scheme 19). Oxidative methods of vegetable oils are extensively reported in the review of Köckritz and Martin ${ }^{99}$. Double bonds were also oxidized (reaction G, Table 1) into allyl hydroperoxides, which were reduced in a second step into secondary hydroxyl functions (reaction $\mathrm{H}$, Table 1). 
Insert Scheme 19: Allyl hydroperoxides synthesis then converted into enone groups or reduced into secondary alcohols

Reaction is performed into a photoreactor equipped with a sodium vapor lamp, under oxygen flow, with thiamine pyrophosphate (TPP) and dichloromethane. Hydroperoxide compound is formed after $4 \mathrm{~h}$ of irradiation. Then reduction is performed with sodium borohydride in methanol at $0^{\circ} \mathrm{C}$. Then, catalytic hydrogenation is performed on platin/carbon $(\mathrm{Pt} / \mathrm{C})$ in ethyl acetate solvent during $3 \mathrm{~h}$.

\section{II.3. Hydroformylation}

The hydroformylation of vegetable oils (reaction E, Table 1) leads to aldehyde functions that can be hydrogenated to yield primary alcohols ${ }^{8}$ (Scheme 20). Hydroformylation step was performed with a rhodium catalyst ${ }^{100,101}$, such as rhodium triphenylphosphine complex ${ }^{82,102}$ or rhodium dicarbonyl acetylacetonate ${ }^{103}$, at $110^{\circ} \mathrm{C}$, under carbon monoxide and hydrogene flow. Hydroformylation was also catalyzed by cobalt complex ${ }^{100}$, but yielded lower conversion (67\% instead of $\left.95 \%\right)$, resulting in polyurethanes with lower mechanical properties. The hydrogenation step (reaction N, Table 1) is generally realized under hydrogen flow with Raney nickel ${ }^{101-103}$. The obtained polyols are directly used in polyurethane synthesis ${ }^{103}$ or are functionalized by further reactions such as esterification ${ }^{104}$. Hydroformylation followed by hydrogenation was also performed on unsaturated fatty acids or esters ${ }^{105}$. Noteworthy, acetalization of the aldehyde function leads to polyacetals ${ }^{106}$.

Insert Scheme 20: Hydroformylation followed by reduction on unsaturated triglyceride

The hydroformylation route, adding a carbon atom on the chain, leads to primary hydroxyl functions compared to epoxide ring opening route that leads to a polyol with a mixture of primary and secondary hydroxyl functions. 
Hydroaminomethylation of fatty esters with various amines was also reported, particularly with valinol, yielding the insertion of secondary amine and primary alcohol on the chain (Scheme 21) ${ }^{107}$.

Insert Scheme 21: Hydroaminomethylation of ethyl oleate by valinol (dioxane, $140^{\circ} \mathrm{C}, 20 \mathrm{~h}$, rhodium complex catalyst, yield 95\%)

This reaction proceeds in three steps through hydroformylation (reaction E, Table 1) followed by condensation of aldehyde function with primary or secondary amine, and then hydrogenation (reaction N, Table 1) yielding secondary or tertiary amine.

\section{II.4. Fatty acids dimerization}

Dimerization of fatty acids is a complex reaction realized at high temperature. The catalysts used are homogeneous such as ionic salts of alkali metals or heterogeneous (most currently used) such as clays (montmorillonite or bentonite) or aluminosilicates $^{108}$. The synthesized dimers are reduced (reaction H, Table 1) to yield fatty diols dimers (Scheme 22). Several mechanisms of dimerization were reported, owing to used fatty acids.

Insert Scheme 22: Fatty acid dimer (left hand) and fatty diol dimer (right hand)

Concerning linoleic acid, reaction proceeds as follows (Scheme 23): a conjugated linoleic acid molecule undergo a Diels-Alder reaction (reaction K, Table 1) with another linoleic acid molecule, yielding a cyclohexene adduct ${ }^{16}$. Conjugated linoleic acid is obtained from isomerization of linoleic acid ${ }^{109-113}$ or by extraction and isolation from some natural oils.

Insert Scheme 23 : Dimerization reaction of conjugated linoleic acid

Concerning oleic acid, dimerization is also possible but proceeds through a different mechanism. Reaction occurs with clay catalyst through protonation of double 
bond. This protonated molecule reacts with another molecule of oleic acid to dimerize (Scheme 24).

Insert Scheme 24: Dimerization reaction of oleic acid

Fatty acid dimers can further be reduced into fatty diol dimers (reaction $\mathrm{H}$ ) in order to confer high hydrophobic, stretching and chemical stability properties to polyurethane synthesized thereof. Diels-Alder reaction with unsaturated conjugated vegetable oils and dienophiles was extensively studied and is industrially performed with maleic anhydride (furan-2,5-dione). Indeed, with Lewis acid such as boron trichloride or stannous tetrachloride and with catalytic quantity of iodine, it is possible to obtain adducts even at low temperature ${ }^{25}$. Metal triflates are also interesting catalysts for the reaction of methyl conjuenoate with butanone, leading to cyclic product with yield higher than $80 \%{ }^{114}$. Moreover, oligomerization and polymerization of soybean oil with diethyl diazenedicarboxylate at room temperature through Diels-Alder reaction was depicted $^{115}$.

Furthermore, cyclic-trimerization of fatty acids was also reported, yielding an aromatic triol with terminal primary hydroxyl functions (Scheme 25) ${ }^{116}$. This synthetic pathway for fatty triols is one of the most interesting since it leads to aromatic molecules from renewable resources ${ }^{25}$.

Insert Scheme 25: Aromatic triols synthesis from (a) methyl-9-octadecenoate and (b) methyl10-undecenoate

\section{II.5. Thiol-ene coupling}

The double bonds of vegetable oils are electron-rich, which allows radical addition of various molecules (Scheme 26) ${ }^{117}$. Thus, thiol-ene coupling (reaction F, Table 1) is an interesting functionalization method.

Insert Scheme 26: Mechanism of thiol-ene coupling 
The literature contains many references to reactions of fats with thiols ${ }^{118}$. Thiol addition is particularly interesting since it may proceed through a photoreaction ${ }^{117,119-}$ 122. Moreover, thiol-ene coupling is poorly sensitive to oxygen and it was evidenced that photoinitiators are not required. This reaction was notably employed to improve antiwear properties of vegetable oils, directly used after thiol-ene coupling ${ }^{53,54,123}$ or after grafting onto metallic surfaces pre-treated with mercaptosilanes ${ }^{124,}{ }^{125}$. Several works studied oligomerization ${ }^{119}$ (Scheme 27) or cross-linking ${ }^{126}$ reactions with polyfunctional thiols.

Insert Scheme 27: Fatty ester trimerization by thiol-ene coupling

Recently, a study reported the synthesis of telechelic alcohols from allyl 10undecenoate by thiol-ene coupling with mercaptoethanol ${ }^{127}$. Another work used either mercaptoethanol or 1-thioglycerol to functionalize methyl undecenoate. The resulting monomers were polymerized to yield polyesters with molecular weights ranging from 4.000 to $10.000 \mathrm{~g} / \mathrm{mol}^{128}$. This technique was also applied to the synthesis of di/tricarboxylic acids used as polyanhydride precursors ${ }^{129}$. The thiol-ene functionalization was also carried out onto polyoxazoline to yield polyols with controlled molecular weight and hydroxyl content ${ }^{130}$ (Scheme 28).

Insert Scheme 28: Synthesis of the poly-2-oxazoline polyols from 10-undecenoic and decanoic acid

A study reported the thiol-ene coupling of 2-mercaptoethanol (2-sulfanylethan1-ol) directly on unsaturated triglycerides to produce interestingly fatty polyols suitable for polyurethane synthesis. In that case, thiol-ene coupling leads in one step to polyols with primary alcohols. This study detailed side-reactions that occurred, leading to various by-products. The mixture of obtained products was directly used in polyurethane synthesis without any purification, since most of by-products are 
hydroxyl-functionalized and react advantageously with diisocyanate molecules (Scheme $29)^{131}$.

Insert Scheme 29: Products and by-products of thiol-ene coupling of 2-mercaptoethanol on fatty acid

The thiol-ene coupling was also applied to synthesize various polyfunctional precursors suitable for polycondensation polymerization ${ }^{132}$, for instance pseudo telechelic diols from fatty methyl esters and mercaptoethanol ${ }^{133,134}$, and polyamines from grapeseed oil and cysteamine ${ }^{135}$.

\section{II.6. Electrophilic additions}

Electrophilic additions are generated from a Lewis acid. Therefore, formaldehyde (methanal) addition onto unsaturated fatty acids yields hydroxylcarboxylic acids (Scheme 30) ${ }^{25,136}$. Friedel-Crafts acylation is also an interesting method to functionalize fatty acids. Indeed, a study reports Friedel-Crafts acylation of oleic acid by acyl chloride with $\mathrm{EtAlCl}_{2}$ yielding $\beta, \gamma$-unsaturated oxocarboxylic acid.

Insert Scheme 30: Formaldehyde addition onto fatty acid

Moreover acylation of undecylenic acid by acyl chlorides or cyclic anhydrides yields unsaturated ketones with carboxylic or hydroxyl terminal group, respectively $\left(\right.$ Scheme 31) ${ }^{136}$.

Insert Scheme 31: Undecylenic acid acylation

Direct alkylation of vegetable oils with phenol in the presence of acid catalysts was also investigated ${ }^{137}$. According to a recent study, side reactions take place during this Friedel-Craft alkylation, such as esterification, oligomerization and Diels Alder reactions. The aromatic-aliphatic polyol mixture obtained was nevertheless used for polyurethane synthesis. 


\section{II.7. Metatesis and alkoxycarbonylation}

The olefin metathesis of natural vegetable oils is a selective catalytic reaction that can efficiently convert oleochemicals into valuable products ${ }^{138,139}$. This reaction provides a convenient route to unsaturated diesters which can be reduced to diols.

A recent study presents the isomerizing alkoxycarbonylation of unsaturated fatty acid esters, yielding $\mathrm{C} 19$ and $\mathrm{C} 23$ diesters. The diesters have been reduced to diols (reaction $\mathrm{H}$, Table 1) using ruthenium as the catalyst in high yield and purity $(>99 \%)$ 140. Polyesters and polyamides were synthesized from the obtained precursors (Scheme 32).

Insert Scheme 32: Linear diols from unsaturated fatty esters alkoxycarbonylation Several functionalization reactions of fatty acids or esters, some of them being advantageously solvent-free, are also reported in the reviewing papers of Schneider ${ }^{25}$, ${ }^{141}$ or Metzger and al. ${ }^{142}$. They are summarized on Scheme 33.

Insert Scheme 33: Double bond modifications for the synthesis of polyols from vegetable oils and derivatives

\section{Reactions of carbonyl group}

The synthesis of polyols from vegetable oils could also be obtained by reaction on ester carbonyl group. Various reactions on carbonyl group of vegetable oils are reported.

\section{III.1. Transesterification}

The choice of the catalyst is the major concern for the transesterification of fatty esters. Bondioli deeply investigated these catalytic reactions and sum up his results in an interesting review ${ }^{143}$. Firstly, transesterification could be catalyzed by homogeneous catalysts. Thus, transesterification reaction (reaction I, Table 1) is generally realized with alkali catalysts ${ }^{144}$ such as sodium methoxyde, sodium or potassium hydroxyde. 
The saponification side-reaction is the main drawback of these catalysts ${ }^{143}$. Hartman reported significant information on different alkali catalysts such as their activity, their solubility, and the saponification rate they entailed ${ }^{145}$. Even if acid catalysis leads to slower reaction time, it is very useful for vegetable oils having a too high acid index ${ }^{146}$. The most currently used acid catalyst for fatty acid esterification is concentrated sulfuric acid ${ }^{147}$, due to a low price and high activity. Moreover, solid catalysts exhibit easier work up and present lower corrosion toward reactors. However both drastic temperature and higher pressure are generally required to reach high yields. These catalysts consist in zeolites, metal oxides, composite materials and polysulfonic acids based on organic materials such as glucose ${ }^{148}$. An interesting review compares these different heterogeneous catalysts owing to their activity, selectivity and thermal stability ${ }^{149}$. On account of these different parameters, zirconium sulfate was found to be one of the best catalysts for biodiesel production. Recent works suggested the use of stannous chloride for saturated and unsaturated fatty acids ethanolysis, reaching yields close to $90 \%$ at temperature around $80^{\circ} \mathrm{C}{ }^{150}$. This cheap catalyst is less corrosive than sulfuric acid and could be re-used during several catalytic cycles. Another method ${ }^{151}$ proposes cupric acetate monohydrate in ethanol with hydrochloric acid, at room temperature, allowing quantitative conversion in one hour.

Beyond ethanol and methanol ${ }^{152,153}$, a lot of different alcohols were used as reagent for the transesterification of fatty esters, such as glycosylated starch ${ }^{154}, 1,4-$ butanediol ${ }^{155}$, a mix of PET/PEG ${ }^{156}$ (polyethyleneterephthalate/polyethyleneglycol), or trimethylolpropane ${ }^{157}$, with various catalysts. Homogeneous ones produce a lot of sideproducts with a low selectivity ${ }^{158}$, whereas heterogeneous ones give better results ${ }^{153}$, ${ }^{159,160}$. The use of glycerin is widespread (Scheme 34), it yields interestingly a mixture 
of mono and di-glycerides that could be directly formulated with diisocyanates with chain extender and catalyst to lead to polyurethanes $3,158,161,162$.

Insert Scheme 34: Transesterification reaction of a triglyceride with glycerin

Sodium methylate was reported ${ }^{163}$ for transesterification reaction of fatty methyl esters with trimethylolpropane, reaching $85 \%$ yield at $110^{\circ} \mathrm{C}$ under reduced pressure. Enzymatic catalysts were also reported ${ }^{163-166}$ but are not detailed in this review.

\section{III.2. Esterification}

In the case of high molecular weight alcohols, it is more interesting to perform a direct esterification of fatty acids (Scheme 35), compared to transesterification, owing to the relative volatility of water and alcohols.

Insert Scheme 35: Esterification reaction on fatty acid

Esterification reaction is generally performed at high temperature (above $200^{\circ} \mathrm{C}$ ) and under reduced pressure ${ }^{143}$. The synthesis of polyols from ricinoleic acid and ethylene glycol was reported ${ }^{167}$ owing a process called fusion without catalyst, at high temperature $\left(230^{\circ} \mathrm{C}\right)$, in order to synthesize polyurethane adhesives. Either acid or basic catalysis are useful for esterification reaction, but they both show some main drawbacks, such as products coloration and salts formation, respectively. Two catalysts are mainly used for the industrial synthesis of polyesters: stannous oxide and zinc powder. Despite their advantages, they also present a disadvantage, i.e. the formation of soluble salts, difficult to remove in esters produced.

Fatty acids of vegetable oils could also be polymerized in a two steps esterification ${ }^{168}$ (Scheme 36). In a first step, alcohol and carboxylic acids functions of fatty acids are condensed through an esterification reaction. Then in a second step, condensed fatty acids are esterified with polyglycerol. This reaction is initiated by a 
polyol, a polyamine or an alcoholamine and is catalyzed by a titan complex or an enzyme ${ }^{169}$.

Insert Scheme 36: Self condensation of fatty acids

\section{III.3. Amidification}

Amidification is also an interesting functionalization reaction on vegetable oils (reaction $\mathrm{J}$, Table 1). Unlike transesterification between alcohols and esters, amidification is not thermodynamically balanced.

Thus, amidification could be performed on fatty acids or esters of vegetable oils with various amines ${ }^{170-173}$. Unsaturated vegetable oils could also react with an alcoholamine and sodium ethoxide at $100^{\circ} \mathrm{C}$, leading to an amide bearing hydroxyl functions $^{82,174,175}$. Example is reported in scheme 37 with castor oil and diethanolamine (2,2'-iminodiethanol). The use of alcoholamine with methyl esters was also reported ${ }^{171}$, thus methyl-9-hydroxystearate and 2-aminoethanol were heated at $85^{\circ} \mathrm{C}$ for $22 \mathrm{~h}$ with potassium hydroxide to yield alcoholamines.

Insert Scheme 37: Synthesis of unsaturated amides by amidification/esterification

\section{III.4. Thioesterification}

Esterification could also proceed with a thiol function through thioesterification reaction. In this case, a difunctional thiol reagent, such as 2-mercaptoethanol, could functionalize vegetable oils, leading to fatty hydroxyl thioesters. A study reported this reaction with 2-mercaptoethanol in isopropanol with sodium or potassium hydroxide ${ }^{176}$ (Scheme 38) but did not mention neither esterification by alcohol, nor thiol-ene addition onto double bonds, which is very surprising, considering the reaction conditions.

Insert Scheme 38: Thioesterification of triglyceride with 2-mercaptoethanol 


\section{III.5. Various reactions}

III.5.1. Fatty alcohols from fatty acids or esters. The reduction of the carboxylic group of a fatty acid or ester by $\mathrm{LiALH}_{4}$ yields a fatty alcohol (reaction $\mathrm{H}$, Table 1), without modifying the unsaturations of the aliphatic chain. These fatty alcohols can also be produced by hydrogenolysis of fatty acids, fatty methyl ester or triacylglycerols ${ }^{177}$. Long chain fatty alcohols generally undergo ethoxylation or propoxylation reactions, leading to interesting surfactant properties (reaction L, Table 1). In a last step, alcohols react with chlorosulfonic acid or phosphoric anhydride to yield sulfates or phosphates surfactants, respectively ${ }^{178}$ (Scheme 39).

Insert Scheme 39: Surfactant synthesis from fatty alcohols

III.5.2. Lactones synthesis. Oleic acid could also be converted into $\gamma$-stearolactone by reaction with perchloric acid at $110^{\circ} \mathrm{C}$ during $3 \mathrm{~h}$ with a yield higher than $90 \%$ (Scheme 40). Reaction mechanism goes through reversible protonation of fatty acid double bonds, shifting and rearrangement of carbocation on chain until the carbonyl group attack. Furthermore, cyclization of methylundecanoate with manganese acetate also yields also a $\gamma$-lactone ${ }^{179}$.

Insert Scheme 40 : Synthesis of $\gamma$-stearolactone

More reactive lactones such as $\delta$-lactones, could also be synthesized from fatty acids bearing double bonds in position 4 or 5, such as 5-eicosenoic acid (20:1). These synthesized lactones could easily react with alcohols or amines to yield respectively hydroxyl esters or hydroxyl amides ${ }^{178}$ (Scheme 41$)$.

Insert Scheme 41: Synthesis of hydroxylesters or hydroxylamides from $\delta$-lactones

Furthermore, polylactones could be synthesized in several steps. For example, methyl oleate, after ozonolysis, hydrogenation, saponification and hydrolysis leads to 9hydroxynonanoic acid. This hydroxyl acid was finally converted into a lactone and then in polynanolactone ${ }^{180,181}$ (Scheme 42). 
Insert Scheme 42: Synthesis of polynonanolactones

III.5.3. AB monomers synthesis. Recently, ricinoleic and oleic acids were used as precursors for $\mathrm{AB}$ monomers synthesis leading to polyurethanes synthesis by direct polycondensation ${ }^{182,183}$ (Scheme 43). This multi-step process goes through an azidation reaction with $\mathrm{NaN}_{3}$ at $0^{\circ} \mathrm{C}$ for $1 \mathrm{~h}$. The next step consists of either a self condensation at $80^{\circ} \mathrm{C}$ for $24 \mathrm{~h}$, or by a transurethane reaction catalyzed by $\mathrm{Ti}(\mathrm{OBu})_{4}$ at $130^{\circ} \mathrm{C}$ for $6 \mathrm{~h}$.

Insert Scheme 43: Synthesis of $\mathrm{AB}$ monomer for polyurethanes synthesis by direct polycondensation

The carboxylic group of fatty compounds offers several ways to insert hydroxyl functions onto triglycerides and fatty acids, as showed in scheme 44.

Insert Scheme 44 : Summary of various products obtained by functionalization of ester group of vegetable oils and derivatives

To conclude, we reported in this part several methods to functionalize natural oils into polyols, through double bonds or carbonyl group of triglycerides. The type of alcohol, the functionality and the route followed for functionalization are crucial parameters for the final properties of synthesized polyurethanes thereof.

\section{Part B: commercial polyols and industrial state of the art}

In this part, we focused on commercial polyols synthesized from renewable resources. Therefore we have been interested in biobased polyols proposed by different industrial companies.

\section{Polyols from saccharides}

Several polyols are synthesized from various monosaccharides and derivatives, such as glucose. Thus, DUPONT has proposed since 2006 CERENOL $^{\mathrm{TM}}$, a polyol dedicated to polyurethanes synthesis for elastomers and fibers. Dupont synthesized biobased 1,3propanediol (Scheme 45 ) from corn by glucose fermentation ${ }^{184}$. CERENOLTM polyol, a 
polytrimethylene ether glycol, is synthesized by step growth polymerization of 1,3propanediol with a homogeneous or heterogeneous catalyst, under reduced pressure and at high temperature (around $\left.200^{\circ} \mathrm{C}\right){ }^{185}$.

Insert Scheme 45: Summary of various products obtained from biomass

ROQUETTE proposes polyols for polyurethanes syntheses such as NEOSORB $\AA$ and POLYSORB $\AA$. NEOSORB $\AA$ is a syrup solution of sorbitol. In the POLYSORB ${ }^{\circledR}$ range, we find a syrup solution of maltitol and sorbitol and also an isosorbide diol (Scheme 45). Sorbitol is coming from hydrogenation of glucose. The sorbitol yields isosorbide with an acid catalyst. These polyols are bearing secondary alcohol groups and they could react with isocyanates to yield polyurethanes. Generally, these polyols are preferably used to synthesize polyols polyethers from alkylene oxide.

\section{Epoxidation of vegetable oils}

Most biobased polyols are synthesized from vegetable oils. And most of them are synthesized from epoxidized vegetable oils.

Thus, JEFFADD ${ }^{\mathrm{TM}} \mathrm{B} 650$ is a biobased polyol, exhibiting $65 \%$ of renewable carbon. This polyol, commercialized since March 2010 by HUNTSMAN Company, is dedicated to polyurethane synthesis for rigid foams, sprays, coatings, adhesives, mastics and elastomers. This polyol is synthesized by the reaction of epoxidized soybean oil bearing 2 to 6 epoxide groups per molecule with an alcohol amine at $120^{\circ} \mathrm{C}$ during 4 hours (reaction $\mathrm{B}$ where $\mathrm{NuH}$ is ethanolamine for instance). Alcohol amines react with epoxide groups and yield a mixture of primary and secondary hydroxyl groups ${ }^{186}$. However, the amine could also react with ester functions of triglycerides by amidification reaction, yielding shorter amide polyols (reaction J, Table 1).

BIOBASED TECHNOLOGIES developed a range of products: AGROL $®$ which is a biobased polyol from soybean oil. AGROL® polyols content of $96 \%$ of 
renewable carbon, owing to ASTMD 6866 standard. The number of hydroxyl group per molecule varies from 2 to 7 owing to different products. AGROL® polyols are synthesized from soybean oil in two steps. In the first step, double bonds of vegetable oils are epoxidized with a peracid (reaction A, Table 1). Oxirane groups are then ringopened by the acid by-product of the first $\operatorname{step}^{187}$ (reaction B, Table 1). AGROL $®$ DIAMOND polyol is prepared from AGROL $\AA$ polyols by aminolysis of ester functions of triglycerides by an alcohol amine (reaction J, Table 1) ${ }^{188}$.This explains the high hydroxyl index of DIAMOND polyols compared to other AGROL polyols (Table 2).

CARGILL has proposed since 2006 a biobased polyol from soybean oil, $\mathrm{BIOH}{ }^{\circledR}$, with a content of renewable carbon higher than $95 \%$ owing to ASTM 6866 standard. Polyurethane flexible foams elaborated with this polyol exhibit a content of renewable carbon between $5 \%$ and $20 \%$. This polyol is synthesized from vegetable oils by epoxidation followed by epoxide ring opening by methanol in presence of fluoroboric acid as catalyst (reaction $\mathrm{B}$, Table 1 where $\mathrm{NuH}$ is $\mathrm{CH}_{3} \mathrm{OH}$ ) ${ }^{189,190}$. Therefore synthesized polyol bears only secondary alcohols functions on aliphatic chain of fatty acid. Even if this structure is similar to castor oil, double bonds are absent from this polyols which improve thermal stability. Two formulations of this polyol are proposed.

COGNIS, and now BASF, proposes an abundant range of biobased polyols from vegetable oils and derivatives under the brand name SOVERMOL ${ }^{\circledR}$ for various applications such as adhesives, binders, floor coatings, castings, electro potting... The chemical route to yield these polyols is also based on epoxidation of vegetable oils followed by ring-opening of epoxides by nucleophilic attack of an alcohol (reaction B, Table 1 where $\mathrm{NuH}$ is $\mathrm{CH}_{3} \mathrm{OH}$ for instance). Then, in a third step, hydoxylated oils undergo transesterification with the same alcohol ${ }^{37}$ (reaction I, Table 1). 
A large range of biobased products from vegetable oils is also proposed by HOBUM OLEOCHEMICALS. This Company functionalizes vegetable oils such as castor oil, linseed oil and soya bean oil, to synthesize polyols by epoxidation followed by nucleophilic attack (reaction B, Table 1). Nucleophilic reagent could be water, alcohol (mono or diol), alcoholamine or amine ${ }^{191}$. These polyols are commercialized under the brand name MERGINOL and are used for polyurethane synthesis for various applications: foams, coatings, dispersions... There are two kinds of polyols in this range, polyester polyols and polyether-polyester polyols.

OLEON, owned by SOFIPROTEOL, commercialize three polyols under the brand name RADIA ${ }^{\circledR}$ (formerly NOVENOL ${ }^{\circledR}$ at NOVANCE): two polyesters polyols for soft polyurethane foams (RADIA ${ }^{\circledR} 7291$ and 7292) and a polyether polyol for rigid polyurethane foam (RADIA ${ }^{\circledR}$ 7293). These polyols are based on different vegetable oils (sunflower, rapeseed, soya bean) and their renewable carbon content varies from $96 \%$ to $100 \%$. Several patents of NOVANCE ${ }^{192,193}$ describe the synthesis of polyols from fatty acids or vegetable oils : double bonds of fatty acids or vegetable oils are epoxidized by hydrogen peroxide with a metal catalyst (molybdenum or tungsten), then the epoxides undergo nucleophilic attack by water ${ }^{194}$ (reaction B, Table 1 where NuH is $\left.\mathrm{H}_{2} \mathrm{O}\right)$.

BAYER develops a biobased polyurethane, BAYDUR ${ }^{\circledR}$ PUL 2500, showing $20 \%$ of renewable carbon and used in flexible and rigid polyurethane foams. It seems that these polyols are synthesized from vegetable oils (preferably soybean oil) by epoxidation followed by hydrogenation to lead secondary alcohols functions (reaction C, Table 1). These alcohol functions are then ethoxylated or propoxylated by alkylene oxide (reaction L, Table 1) with metal cyanide in order to lead to primary alcohol 
functions ${ }^{195}$. Another patent of BAYER describes alkoxylation of hydroxylated vegetable oils, whatever the hydroxylation method ${ }^{196}$.

Insert Table 2: Properties of commercial polyols from vegetable oils epoxidation

\section{Various functionalization reactions of vegetable oils}

DOW CHEMICAL started the production of biobased Renuva ${ }^{\mathrm{TM}}$ polyol, synthesized from soybean oil, used for flexible foams, coatings, adhesives, mastics and elastomers. This polyol is synthesized in several steps. Firstly, soybean oil undergoes transesterification with methanol (reaction I) to yield fatty acids methyl esters (FAMEs). In a second step, by hydroformylation followed by hydrogenation (reaction E), double bonds of these FAMEs are converted in hydroxyl groups. The hydroxyl content depends on the number of double bonds in starting oil. In a third step, these hydroxylated FAMEs react with a polyols (such as propan-1,2,3-triol) or a polyamine (such as 1,2-diaminoethane) with a catalyst during about 5 hours under vacuum ${ }^{169,197}$ (reaction I or J, Table 1). Owing to recent information from Dow Europe, the production of this polyol has been stopped due to a too high variability of fatty acids double bonds composition. Therefore FAMEs with different hydroxyl contents had to be separated before polyols synthesis which entails a too high price for this process.

Concerning BASF, this Company produces LUPRANOL® BALANCE 50, a polyether polyol for rigid foams and mattress that partly comes from castor oil. And now BASF develops Lupranol Balance 35, synthesized by hydroformylation (rhodium or cobalt catalyst) followed by hydrogenation (nickel based catalyst) on castor oil (reaction E, Table 1). This polyol is then etherified (reaction L, Table 1) with alkylene oxide (ethylene or de propylene oxide) with double metal cyanide catalyst (Scheme 46). Another polyol polyether is added for the elaboration of polyurethane foams ${ }^{198}$.

Insert Scheme 46: Structure of Lupranol® Balance 50 polyol 
The functionality of Lupranol is surprisingly claimed lower than 3, whereas the process used by BASF could lead to around 6 hydroxyl groups per molecule. It seems that secondary hydroxyl groups are considered as non reactive, not only towards ethoxylation/propolxylation, but also towards polyurethanes synthesis.

COGNIS also proposes biobased polyols from fatty acid dimers, under the brand

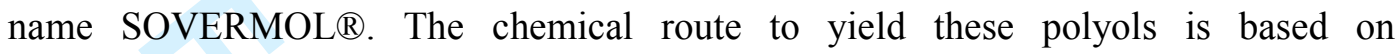
dimerization fatty acids catalyzed by montmorillonite clay at $250^{\circ} \mathrm{C}$ (Scheme 24), followed by reduction of carboxylic acid groups into alcohol functions ${ }^{199}$ (reaction H, Table 1).

The US Company URETHANE SOY SYSTEMS proposes biobased SOYOL polyols from soybean oil used in various polyurethane applications: foams, sealing, coatings... The process is based on transesterification of triglycerides with propan1,2,3-triol previously modified with saccharide (reaction I, Table 1) ${ }^{200}$.

CRODA sells several biobased products such as PRIPOL ${ }^{\mathrm{TM}}$ fatty acids dimers and PRIPLAST ${ }^{\mathrm{TM}}$ polyether polyols, with a renewable carbon content between $36 \%$ and $100 \%$ owing to the formulation. The chemical synthesis of fatty acids dimers was described previously (Scheme 24) CRODA uses acid catalyst at high temperature ${ }^{201}$. Diols dimers are obtained by reduction $\left(\mathrm{H}_{2}\right.$ with nickel) of carboxylic acid function of fatty acids dimers ${ }^{202}$ (reaction H, Table 1). Noteworthy, no double bond remains in the final diols.

MITSUI patented the synthesis of biobased polyols for polyurethane by transesterification of fatty acids with short polyols (reaction I, Table 1) followed by ethoxylation or propoxylation of terminal hydroxyl groups ${ }^{203}$ (reaction L, Table 1).

Table 3 : properties of commercial polyols from various reactions on vegetable oils 


\section{CONCLUSION}

This review shows that biobased polyols have an important place in the Polyurethanes industry. Indeed, most of biggest chemical groups have developed their own brand of biobased polyols, offering to users new various reactive polyols in order to increase renewable carbon content of final materials. In a first part, the present review goes into details of the different synthetic routes to obtain polyols from vegetable oils. Indeed, Part A describes several methods to graft hydroxyl functions onto vegetable oils and derivatives, owing to their epoxy groups (Scheme 17), double bond sites (Scheme 33) and/or carboxyl functions (Scheme 44).

In a second part, the present review is dedicated to the commercial biobased polyols, and, based on the patent literature; focus on the industrial synthetic routes. Indeed Part B sheds lights on the importance of biobased polyols in polyurethanes industry. The number of patents in this domain is one of the proofs of the main role of biobased polyols in industrial polyurethanes.

Among all these methods, epoxidation followed by epoxide ring opening remains the most currently used and patented method, due to the variety of usable nucleophiles in this reaction. Conversely, thiol-ene chemistry is not yet used at the industrial level despite the advantages reported in the first part. The use of biobased polyols for the manufacture of polyurethanes is a real positive point for the environmental impact of polymers. It is all the more interesting to use biobased polyols in PU synthesis since polyols represent the major part of PU, generally between 60 to $70 \%$ in weight of PU.

Vegetable oils and fats are very important resources for polyols. The vegetable oils with a worldwide production of around 150 million t/year (in 2009 - data from FAO), are used mainly in human food applications (75\%). But the technical uses and particularly oleochemical industry are increasing. (13\% is used in oleochemical 
industry). Vegetable oils lead to polyester polyols. And polyester polyols are the second most important group of oligopolyols for the production of polyurethanes. The production of polyester polyols, with a total worldwide production of around $600 \mathrm{kt} /$ year, represents around $18 \%$ of the polyols used globally in polyurethanes. Moreover, about $60 \%$ of polyester polyols are produced in Europe ${ }^{204}$. Polyester polyols were the only polyols available to the polyurethanes industry at the beginning, but now, in spite of the leading position of polyethers in the total polyols usage in the polyurethane industry, polyester polyols have stable and specific practical applications due to some superior characteristics of the resulting polyurethanes ${ }^{204}$. Indeed, the superior characteristics of polyester polyol based polyurethanes are explained by a better crystalline structure in the urethane segment, compared to the majority of polyether polyols which are amorphous, due to the superior secondary forces between the polyester chains and also due to a superior thermal and fire resistance, compared to polyether polyol based polyurethanes. Polyesterbased polyurethanes (flexible foams, coatings), have a superior solvent resistance compared to the polyether-based polyurethanes $^{205}$.

Indeed, purity of triglycerides from vegetable oils could be discussed. But in a near future, new production units will be installed, for producing high-purity fatty esters and acids (such as Pivert in Compiègne, France), giving an easy industrial access to diols for linear PU based on chemical pathways depicted in this manuscript. And even if one of the limitations of polyester polyols consists of their sensitivity to hydrolysis, the the use of fatty alcohols to build the polyester structure, creates an extremely high hydrophobic environment alongside a low concentration of labile ester bonds and improves hydrolysis resistance. 
2

3

4

5

6

7

8

9

10

11

12

13

14

15

16

17

18

19

20

21

22

23

24

25

26

27

28

29

30

31

32

33

34

35

36

37

38

39

40

41

42

43

44

45

46

47

48

49

50

51

52

53

54

55

56

57

58

59

60

However, isocyanates are still used and are generally very harmful for human health, particularly for people exposed during polyurethanes synthesis, and could entail adverse health effects such as asthma, dermatitis, conjunctivitis and acute poisoning. Moreover, REACH regulation prevents the use of major isocyanates such as methylene diphenyl diisocyanate MDI and toluene diisocyanate TDI ${ }^{206}$. Therefore the synthesis of Polyurethanes from step growth polyaddition of dicyclocarbonates and diamines should be favored. Thus, this old reaction is currently gaining a lot of attention as a substitution route for the synthesis of Polyurethanes and will be industrialized in a next future.

URL: http://mc.manuscriptcentral.com/LMSC Email: polyreviews@bellsouth.net 


\section{References}

1. Genas, M. "Rilsan (Polyamid 11), Synthese und Eigenschaften", Angew. Chem. 1962, 74, 535-540.

2. Shen, L.; Haufe, J.; Patel, M. K. 2009. Product overview and market projection of emerging bio-based plastics, Utrecht University commissioned by European Polysaccharide Network of Excellence and European Bioplastics.

3. Campanella, A.; Bonnaillie, L. M.; Wool, R. P. "Polyurethane foams from soyoil-based polyols", J. Appl. Polym. Sci. 2009, 112, 2567-2578.

4. Zlatanic, A.; Lava, C.; Zhang, W.; Petrovic, Z. S. "Effect of structure on properties of polyols and polyurethanes based on different vegetable oils", $J$. Polym. Sci., Part B : Polym. Phys. 2004, 42, 809-819.

5. Miao, S.; Zhang, S.; Su, Z.; Wang, P. "A novel vegetable oil-lactate hybrid monomer for synthesis of high-Tg polyurethanes", J. Polym. Sci., Part A : Polym. Chem. 2010, 48, 243-250.

6. Ionescu, M. Chemistry and technology of polyols for polyurethanes; Rapra Technology Limited. 2005.

7. Lligadas, G.; Ronda, J. C.; Galià, M.; Càdiz, V. "Plant Oils as Platform Chemicals for Polyurethane Synthesis: Current State-of-the-Art", Biomacromolecules 2010, 11, 2825-2835.

8. Sharma, V.; Kundu, P. P. "Condensation polymers from natural oils", Prog. Polym. Sci. 2008, 33, 1199-1215.

9. Lligadas, G.; Ronda, J. C.; Galià, M.; Cadiz, V. "Oleic and Undecylenic Acids as Renewable Feedstocks in the Synthesis of Polyols and Polyurethanes", Polymers 2010, 2, 440-453.

10. Ronda, J. C.; Lligadas, G.; Galià, M.; Cádiz, V. "Vegetable oils as platform chemicals for polymer synthesis", Eur. J. Lipid Sci. Technol. 2011, 113, 46-58.

11. González-Paz, R. J.; Lluch, C.; Lligadas, G.; Ronda, J. C.; Galià, M.; Cádiz, V. "A green approach toward oleic- and undecylenic acid-derived polyurethanes", J. Polym. Sci., Part A: Polym. Chem. 2011, 49, 2407-2416.

12. Gandini, A. "Polymers from Renewable Resources: A Challenge for the Future of Macromolecular Materials", Macromolecules 2008, 41, 9491-9504.

13. Petrovic, Z. S. "Polyurethanes from Vegetable Oils", Polym. Rev. 2008, 48, 109 $-155$.

14. Raquez, J. M.; Deléglise, M.; Lacrampe, M. F.; Krawczak, P. "Thermosetting (bio)materials derived from renewable resources : a critical review", Prog. Polym. Sci. 2010, 35, 487-509.

15. Montero de Espinosa, L.; Meier, M. A. R. "Plant oils: The perfect renewable resource for polymer science?!" Eur. Polym. J. 2011, 47, 837-852.

16. Seniha Güner, F.; YagcI, Y.; Tuncer Erciyes, A. "Polymers from triglyceride oils", Prog. Polym. Sci. 2006, 31, 633-670.

17. Meier, M. A. R.; Metzger, J. O.; Schubert, U. S. "Plant oil renewable resources as green alternatives in polymer science", Chem. Soc. Rev. 2007, 36, 1788-1802.

18. Galià, M.; de Espinosa, L. M.; Ronda, J. C.; Lligadas, G.; Cádiz, V. "Vegetable oil-based thermosetting polymers", Eur. J. Lipid Sci. Technol. 2010, 112, 87-96.

19. Pfister, D. P.; Xia, Y.; Larock, R. C. "Recent Advances in Vegetable Oil-Based Polyurethanes", ChemSusChem 2011, 4, 703-717.

20. Tu, Y.-C.; Suppes, G. J.; Hsieh, F.-h. "Thermal and mechanical behavior of flexible polyurethane-molded plastic films and water-blown foams with epoxidized soybean oil", J. Appl. Polym. Sci. 2009, 111, 1311-1317. 
21. Tan, S. G.; Chow, W. S. "Biobased Epoxidized Vegetable Oils and Its Greener Epoxy Blends: A Review", Polymer-Plastics Technol. Eng. 2010, 49, 15811590.

22. Zlatanic, A.; Petrovic, Z. S.; Dusek, K. "Structure and Properties of TrioleinBased Polyurethane Networks", Biomarcomolecules 2002, 3, 1048-1056.

23. Lie Ken Jie, M.; Yan-Kit, C. "The use of a microwave oven in the chemical transformation of long chain fatty acid esters", Lipids 1988, 23, 367-369.

24. Piazza, G.; Foglia, T. "Preparation of fatty amide polyols via epoxidation of vegetable oil amides by oat seed peroxygenase", J. Am. Oil Chem. Soc. 2005, $82,481-485$.

25. Biermann, U.; Friedt, W.; Lang, S.; Lühs, W.; Machmüller, G.; Metzger, J. O.; gen, M. R.; Hans, K.; Schäfer, J.; Schneider, M. P. "New Syntheses with Oils and Fats as Renewable Raw Materials for the Chemical Industry", Angew. Chem., Int. Ed. 2000, 39, 2206-2224.

26. Rüsch gen. Klaas, M.; Warwel, S. "Complete and partial epoxidation of plant oils by lipase-catalyzed perhydrolysis", Ind. Crops Prod. 1999, 9, 125-132.

27. Ahmad, S.; Ashraf, S. M.; Sharmin, E.; Zafar, F.; Hasnat, A. "Studies on ambient cured polyurethane modified epoxy coatings synthesized from a sustainable resource", Prog. Cryst. Growth Charact. Mater. 2002, 45, 83-88.

28. Harry-O'kuru, R. E.; Carriere, C. J. "Synthesis, Rheological Characterization, and Constitutive Modeling of Polyhydroxy Triglycerides Derived from Milkweed Oil", J. Agric. Food Chem. 2002, 50, 3214-3221.

29. Harry-O'kuru, R. E.; Holser, R. A.; Abbott, T. P.; Weisleder, D. "Synthesis and characteristics of polyhydroxy triglycerides from milkweed oil", Ind. Crops Prod. 2002, 15, 51-58.

30. Dwan'isa, J. P. L.; Mohanty, A. K.; Misra, M.; Drzal, L. T.; Kazemizadeh, M. "Novel soy oil based polyurethane composites: Fabrication and dynamic mechanical properties evaluation", J. Mater. Sci. 2004, 39, 1887-1890.

31. Adhvaryu, A.; Liu, Z.; Erhan, S. Z. "Synthesis of novel alkoxylated triacylglycerols and their lubricant base oil properties", Ind. Crops Prod. 2005, 21, 113-119.

32. Erhan, S. Z.; Adhvaryu, A.; Liu, Z. "Chemically modified vegetable oil-based industrial fluid", US 2003/6583302.

33. Adhvaryu, A.; Erhan, S. Z.; Perez, J. M. "Tribological studies of thermally and chemically modified vegetable oils for use as environmentally friendly lubricants", Wear 2004, 257, 359-367.

34. Sharma, B.; Adhvaryu, A.; Liu, Z.; Erhan, S. "Chemical modification of vegetable oils for lubricant applications", J. Am. Oil Chem. Soc. 2006, 83, 129136.

35. Wang, L.; Wang, T. "Chemical Modification of Partially Hydrogenated Vegetable Oil to Improve its Functional Properties for Candles", J. Am. Oil Chem. Soc. 2007, 84, 1149-1159.

36. Geiger, E. J.; Becker, N. M.; Armbruster, L. A. "Novel polyols derived from a vegetable oil using an oxidation process", US 2006/007724.

37. Kluth, H.; Gruber, B.; Meffert, A.; Huebner, W. "Polyurethane prepolymers based on oleochemical polyols, their production and use", US 1988/4,742,087.

38. Kluth, H.; Meffert, A. "Polyurethane prepolymers based on oleochemical polyols", US 1985/4,508,853.

39. Meffert, A.; Kluth, H. "Process for the preparation of modified triglycerides", US 1989/4,886,893. 
40. Shani, A. "Functionalization at the double-bond region of jojoba oil. 3 . Hydroxylic derivatives", Ind. Eng. Chem. Prod. Res. Dev. 1983, 22, 121-123.

41. Hwang, H.-S.; Erhan, S. "Modification of epoxidized soybean oil for lubricant formulations with improved oxidative stability and low pour point", J. Am. Oil Chem. Soc. 2001, 78, 1179-1184.

42. Hwang, H.-S.; Adhvaryu, A.; Erhan, S. "Preparation and properties of lubricant basestocks from epoxidized soybean oil and 2-ethylhexanol", J. Am. Oil Chem. Soc. 2003, 80, 811-815.

43. Petrovic, Z.; Javni, I.; Guo, A.; Zhang, W. "Method of making natural oil based polyols and polyurethanes therefrom", US 2002/6,433,121.

44. Petrovic, Z.; Guo, A.; Javni, I. "Process for the preparation of vegetable oil based polyols and electroninsulating casting compounds created from vegetable oil based polyols", US 2000/6,107,433.

45. Ionescu, M.; Petrović, Z.; Wan, X. "Ethoxylated Soybean Polyols for Polyurethanes", J. Polym. Environ. 2007, 15, 237-243.

46. Lu, Y.; Larock, R. C. "Soybean-Oil-Based Waterborne Polyurethane Dispersions: Effects of Polyol Functionality and Hard Segment Content on Properties", Biomarcomolecules 2008, 9, 3332-3340.

47. Petrovic, Z.; Javni, I.; Zlatanic, A.; Guo, A. "Modified vegetable oil-based polyols", WO 2006/012344.

48. Javni, I.; Zhang, W.; Petrovic, Z. "Effect of different isocyanates on the properties of soy-based polyurethanes", J. Appl. Polym. Sci. 2003, 88, 29122916.

49. Lu, Y.; Larock, R. "Aqueous Cationic Polyurethane Dispersions from Vegetable Oils", ChemSusChem 2009, 3, 329-333.

50. Chasar, D. W.; Hughes, M. J. "Method of making oleochemical oil-based polyols", WO 2003/029182 A1.

51. Lathi, P. S.; Mattiasson, B. "Green approach for the preparation of biodegradable lubricant base stock from epoxidized vegetable oil", Appl. Catal. B: Environ. 2007, 69, 207-212.

52. Lligadas, G.; Ronda, J. C.; Galià, M.; Biermann, U.; Metzger, J. O. "Synthesis and characterization of polyurethanes from epoxidized methyl oleate based polyether polyols as renewable resources", J. Polym. Sci., Part A: Polym. Chem. 2006, 44, 634-645.

53. Erhan, S. Z.; Adhvaryu, A.; Sharma, B. K. "Poly(hydroxy thioethers) vegetable oil derivatives useful as lubricant additives", US 2006/0,009,365.

54. Sharma, B. K.; Adhvaryu, A.; Erhan, S. Z. "Synthesis of Hydroxy Thio-ether Derivatives of Vegetable Oil", J. Agric. Food Chem. 2006, 54, 9866-9872.

55. Chen, Z.; Chisholm, B.; Patani, R.; Wu, J.; Fernando, S.; Jogodzinski, K.; Webster, D. "Soy-based UV-curable thiol-ene coatings", J. Coat. Technol. Res. 2010, 7, 603-613.

56. Biswas, A.; Adhvaryu, A.; Gordon, S. H.; Erhan, S. Z.; Willett, J. L. "Synthesis of Diethylamine-Functionalized Soybean Oil", J. Agric. Food Chem. 2005, 53, 9485-9490.

57. Petrovic, Z.; Guo, A.; Zhang, W. "Structure and properties of polyurethanes based on halogenated and nonhalogenated soy-polyols", J. Appl. Polym. Sci. 2000, 38, 4062-4069.

58. Guo, A.; Cho, Y.; Petrovic, Z. S. "Structure and properties of halogenated and nonhalogenated soy-based polyols", J. Appl. Polym. Sci. 2000, 38, 3900-3910. 
59. Scholnick, F.; Saggese, E.; Wrigley, A.; Ault, W.; Monroe, H.; Zubillaga, M. "Urethane foams from animal fats. IV. Rigid foams from epoxidized glycerides", J. Am. Oil Chem. Soc. 1968, 45, 76-77.

60. Scholnick, F.; Saggese, E.; Wrigley, A.; Riser, G. "Urethane foams from animal fats: V. Flame resistant foams from hypohalogenated glycerides", J. Am. Oil Chem. Soc. 1970, 47, 180-182.

61. Kiatsimkul, P.-p.; Suppes, G. J.; Hsieh, F.-h.; Lozada, Z.; Tu, Y.-C. "Preparation of high hydroxyl equivalent weight polyols from vegetable oils", Ind. Crops Prod. 2008, 27, 257-264.

62. Campanella, A.; Rustoy, E.; Baldessari, A.; Baltanás, M. A. "Lubricants from chemically modified vegetable oils", Biores. Technol. 2009, 101, 245-254.

63. Hüseyin Esen, S. H. K.; gbreve; lu "Photolytic and free-radical polymerization of cinnamate esters of epoxidized plant oil triglycerides", J. Appl. Polym. Sci. 2003, 89, 3882-3888.

64. Pelletier, H.; Belgacem, N.; Gandini, A. "Acrylated vegetable oils as photocrosslinkable materials", J. Appl. Polym. Sci. 2006, 99, 3218-3221.

65. Erhan, S. Z.; Doll, K.; Sharma, B. "Method of making fatty acid ester derivatives", WO 2008/079901 A1.

66. Erhan, S. Z.; Sharma, B. K.; Liu, Z.; Adhvaryu, A. "Lubricant Base Stock Potential of Chemically Modified Vegetable Oils", J. Agric. Food Chem. 2008, $56,8919-8925$.

67. Doll, K. M.; Sharma, B. K.; Erhan, S. Z. "Synthesis of Branched Methyl Hydroxy Stearates Including an Ester from Bio-Based Levulinic Acid", Ind. Eng. Chem. Res. 2007, 46, 3513-3519.

68. Sharma, B. K.; Doll, K. M.; Erhan, S. Z. "Ester hydroxy derivatives of methyl oleate: Tribological, oxidation and low temperature properties", Biores. Technol. 2008, 99, 7333-7340.

69. Moser, B.; Sharma, B.; Doll, K.; Erhan, S. "Diesters from Oleic Acid: Synthesis, Low Temperature Properties, and Oxidation Stability", J. Am. Oil Chem. Soc. 2007, 84, 675-680.

70. Petrovic, Z. S.; Yang, L.; Zlatanic, A.; Zhang, W.; Javni, I. "Network structure and properties of polyurethanes from soybean oil", J. Appl. Polym. Sci. 2007, 105, 2717-2727.

71. Cheong, M. Y.; Ooi, T. L.; Ahmad, S.; Yunus, W. M. Z. W.; Kuang, D. "Synthesis and characterization of palm-based resin for UV coating", J. Appl. Polym. Sci. 2009, 111, 2353-2361.

72. Dai, H.; Yang, L.; Lin, B.; Wang, C.; Shi, G. "Synthesis and Characterization of the Different Soy-Based Polyols by Ring Opening of Epoxidized Soybean Oil with Methanol, 1,2-Ethanediol and 1,2-Propanediol", J. Am. Oil Chem. Soc. 2009, 86, 261-267.

73. Abraham, T., W.; Dai, D., G.; De Genova, R.; Malsam, J. "Viscoelastic polyurethane foams comprising oligomeric natural oil polyols", WO 2008/063594 A1.

74. Choi, S. W.; Wan Seo, D.; Don Lim, Y.; Gi Jeong, Y.; Islam Mollah, M. S.; Park, H.; Whan Hong, T.; Gi Kim, W. "Synthesis and properties of multihydroxy soybean oil from soybean oil and polymeric methylene-diphenyl4,4'-diisocyanate/multihydroxy soybean oil polyurethane adhesive to wood", $J$. Appl. Polym. Sci. 2011, 121, 764-769. 
75. Abu Hassan, H.; Tuan Ismail, T. N. M.; Sattar, M. N.; Hoong, S. S.; Ooi, T. L.; Ahmad, S.; Poo Palam, K. D.; Cheong, M. Y. "Process to produce polyols", US 2008/0,293,913 A1.

76. Cramail, H.; Boyer, A.; Cloutet, E.; Bakhiyi, R.; Alfos, C. "Novel method for preparing polyols and products obtained", WO 2011/030076 A1.

77. Hu, Y. H.; Gao, Y.; Wang, D. N.; Hu, C. P.; Zu, S.; Vanoverloop, L.; Randall, D. "Rigid polyurethane foam prepared from a rape seed oil based polyol", $J$. Appl. Polym. Sci. 2002, 84, 591-597.

78. Dahlke, B.; Hellbardt, S.; Paetow, M.; Zech, W. "Polyhydroxy fatty acids and their derivatives from plant oils", J. Am. Oil Chem. Soc. 1995, 72, 349-353.

79. Lee, C.; Ooi, T.; Chuah, C.; Ahmad, S. "Synthesis of Palm Oil-Based Diethanolamides", J. Am. Oil Chem. Soc. 2007, 84, 945-952.

80. Ramirez-de-Arellano-Aburto, N.; Cohen-Barki, A.; Cruz-Gomez, M. J. "Process for the production of oleochemical polyols", US 2002/0,099,230.

81. Kolancilar, H. "Preparation of laurel oil alkanolamide from laurel oil", J. Am. Oil Chem. Soc. 2004, 81, 597-598.

82. Khoe, T.; Otey, F.; Frankel, E.; Cowan, J. "Polyurethane foams from hydroxymethylated fatty diethanolamides", J. Am. Oil Chem. Soc. 1973, 50, 331-333.

83. Lee, C.; Ooi, T.; Chuah, C.; Ahmad, S. "Rigid Polyurethane Foam Production from Palm Oil-Based Epoxidized Diethanolamides", J. Am. Oil Chem. Soc. 2007, 84, 1161-1167.

84. Waidner, T. C.; Granquist, V. M. "Novel polyol-polyamine synthesized from vegetable oils", US 2007/0,155,934.

85. Bilyk, A.; Monroe, H.; Saggese, E.; Zubillaga, M.; Wrigley, A. "Urethane foams from animal fats: IX. Polyols based upon tallow and trimethylolpropane; preparation under acidic and basic catalysis", J. Am. Oil Chem. Soc. 1975, 52, 289-292.

86. Li, Z.; Zhao, Y.; Yan, S.; Wang, X.; Kang, M.; Wang, J.; Xiang, H. "Catalytic Synthesis of Carbonated Soybean Oil", Catal. Lett. 2008, 123, 246-251.

87. Jalilian, M.; Yeganeh, H.; Haghighi, M. N. "Synthesis and properties of polyurethane networks derived from new soybean oil-based polyol and a bulky blocked polyisocyanate", Polym. Int. 2008, 57, 1385-1394.

88. Parzuchowski, P. G.; Jurczyk-Kowalska, M.; Ryszkowska, J.; Rokicki, G. "Epoxy resin modified with soybean oil containing cyclic carbonate groups", $J$. Appl. Polym. Sci. 2006, 102, 2904-2914.

89. Javni, I.; Hong, D. P.; Petrović, Z. S. "Soy-based polyurethanes by nonisocyanate route", J. Appl. Polym. Sci. 2008, 108, 3867-3875.

90. Guan, J.; Song, Y.; Lin, Y.; Yin, X.; Zuo, M.; Zhao, Y.; Tao, X.; Zheng, Q. "Progress in study of non-isocyanate polyurethane", Ind. Eng. Chem. Res. 2011, 50, 6517-6527.

91. Ramani, N.; Graiver, D.; Farminer, K. W.; Tran, P. T.; Tran, T. "Novel modified fatty acid esters and method of preparation thereof", US 2010/0,084,603 A1.

92. Petrovic, Z. S.; Zhang, W.; Javni, I. "Structure and Properties of Polyurethanes Prepared from Triglyceride Polyols by Ozonolysis", Biomarcomolecules 2005, 6, 713-719.

93. Petrovic, Z. S.; Milic, J.; Xu, Y.; Cvetkovic, I. "A Chemical Route to High Molecular Weight Vegetable Oil-Based Polyhydroxyalkanoate", Macromolecules 2010, 43, 4120-4125. 
94. Narine, S.; Yue, J.; Kong, X. "Production of Polyols from Canola Oil and their Chemical Identification and Physical Properties", J. Am. Oil Chem. Soc. 2007, 84, 173-179.

95. Kong, X.; Yue, J.; Narine, S. S. "Physical Properties of Canola Oil Based Polyurethane Networks", Biomarcomolecules 2007, 8, 3584-3589.

96. Pechar, T. W.; Sohn, S.; Wilkes, G. L.; Ghosh, S.; Frazier, C. E.; Fornof, A.; Long, T. E. "Characterization and comparison of polyurethane networks prepared using soybean-based polyols with varying hydroxyl content and their blends with petroleum-based polyols", J. Appl. Polym. Sci. 2006, 101, 14321443.

97. Tu, Y.-C.; Kiatsimkul, P.; Suppes, G. J.; Hsieh, F.-H. "Physical properties of water-blown rigid polyurethane foams from vegetable oil-based polyols", $J$. Appl. Polym. Sci. 2007, 105, 453-459.

98. John, J.; Bhattacharya, M.; Turner, R. B. "Characterization of polyurethane foams from soybean oil", J. Appl. Polym. Sci. 2002, 86, 3097-3107.

99. Köckritz, A.; Martin, A. "Oxidation of unsaturated fatty acid derivatives and vegetable oils", Eur. J. Lipid Sci. Technol. 2008, 110, 812-824.

100. Guo, A.; Demydov, D.; Zhang, W.; Petrovic, Z. S. "Polyols and Polyurethanes from Hydroformylation of Soybean Oil", J. Polym. Environ. 2002, 10, 49-52.

101. Lyon, C.; Garrett, V.; Frankel, E. "Rigid urethane foams from hydroxymethylated castor oil, safflower oil, oleic safflower oil, and polyol esters of castor acids", J. Am. Oil Chem. Soc. 1974, 51, 331-334.

102. Khoe, T.; Otey, F.; Frankel, E. "Rigid urethane foams from hydroxymethylated linseed oil and polyol esters", J. Am. Oil Chem. Soc. 1972, 49, 615-618.

103. Guo, A.; Zhang, W.; Petrovic, Z. "Structure-property relationships in polyurethanes derived from soybean oil", J. Mater. Sci. 2006, 41, 4914-4920.

104. Petrovic, Z.; Guo, A.; Javni, I.; Cvetkovic, I.; Hong, D. P. "Polyurethane networks from polyols obtained by hydroformylation of soybean oil", Polym. Int. 2008, 57, 275-281.

105. Prange, R.; Sonnenschein, M.; Babb, D. A.; Schrock, A. K. "Polyurethane foams made from hydroxymethyl-containing polyester polyols and tertiary aminecontaining polyols", WO 2008/039657 A1.

106. Khoe, T.; Gast, L.; Frankel, E.; Cowan, J. "New polyacetal, poly(ester-acetal) and their urethane-modified coatings from hydroformylated linseed oil", J. Am. Oil Chem. Soc. 1972, 49, 134-136.

107. Behr, A.; Fiene, M.; Buß, C.; Eilbracht, P. "Hydroaminomethylation of fatty acids with primary and secondary amines - A new route to interesting surfactant substrates", Eur. J. Lipid Sci. Technol. 2000, 102, 467-471.

108. Tolvanen, P.; Mäki-Arvela, P.; Kumar, N.; Eränen, K.; Sjöholm, R.; Hemming, J.; Holmbom, B.; Salmi, T.; Murzin, D. Y. "Thermal and catalytic oligomerisation of fatty acids", Appl. Catal. A: General 2007, 330, 1-11.

109. Larock, R.; Dong, X.; Chung, S.; Reddy, C.; Ehlers, L. "Preparation of conjugated soybean oil and other natural oils and fatty acids by homogeneous transition metal catalysis", J. Am. Oil Chem. Soc. 2001, 78, 447-453.

110. Jain, V. P.; Proctor, A. "Photocatalytic Production and Processing of Conjugated Linoleic Acid-Rich Soy Oil", J. Agric. Food Chem. 2006, 54, 5590-5596.

111. Gammill, W.; Proctor, A.; Jain, V. "Comparative Study of High-Linoleic Acid Vegetable Oils for the Production of Conjugated Linoleic Acid", J. Agric. Food Chem. 2010, 58, 2952-2957. 
112. Gangidi, R.; Proctor, A. "Photochemical production of conjugated linoleic acid from soybean oil", Lipids 2004, 39, 577-582.

113. Yang, T.-S.; Liu, T.-T. "Optimization of Production of Conjugated Linoleic Acid from Soybean Oil", J. Agric. Food Chem. 2004, 52, 5079-5084.

114. Behr, A.; Fiene, M.; Naendrup, F.; Schürmann, K. "Transition-metal trifluoromethane-sulphonates-recyclable catalysts for the synthesis of branched fatty derivatives by Diels-Alder reactions at unsaturated fatty esters", Eur. J. Lipid Sci. Technol. 2000, 102, 342-350.

115. Biswas, A.; Sharma, B. K.; Willett, J. L.; Erhan, S. Z.; Cheng, H. N. "Roomtemperature self-curing ene reactions involving soybean oil", Green Chem. 2008, 10, 290-295.

116. Lligadas, G.; Ronda, J. C.; Galia, M.; Cadiz, V. "Polyurethane Networks from Fatty-Acid-Based Aromatic Triols : Synthesis and Characterization", Biomarcomolecules 2007, 8, 1858-1864.

117. Bantchev, G. B.; Kenar, J. A.; Biresaw, G.; Han, M. G. "Free Radical Addition of Butanethiol to Vegetable Oil Double Bonds", J. Agric. Food Chem. 2009, 57, 1282-1290.

118. Koenig, N. H.; Swern, D. "Organic sulfur derivatives. I. Addition of mercaptoacetic acid to long-chain monounsaturated compounds", J. Am. Chem. Soc. 1957, 79, 362-365.

119. Samuelsson, J.; Jonsson, M.; Brinck, T.; Johansson, M. "Thiol-ene coupling reaction of fatty acid monomers", J. Polym. Sci., Part A : Polym. Chem. 2004, 42, 6346-6352.

120. Wasson, J. I. "Compositions containing and process for preparing stabilized unsaturated fatty oils", US 1950/2,522,476.

121. Walling, C. "Preparing organic suflides", US 1948/2,454,108.

122. Schwab, A.; Gast, L.; Cowan, J. "Free radical addition of hydrogen sulfide and thiols to linseed oil and methyl oleate", J. Am. Oil Chem. Soc. 1968, 45, 461464.

123. Sharma, B. K.; Adhvaryu, A.; Erhan, S. Z. "Friction and wear behavior of thioether hydroxy vegetable oil", Tribol. Int. 2009, 42, 353-358.

124. Bexell, U.; Olsson, M.; Johansson, M.; Samuelsson, J.; Sundell, P.-E. "A tribological study of a novel pre-treatment with linseed oil bonded to mercaptosilane treated aluminium", Surf. Coat. Technol. 2003, 166, 141-152.

125. Bexell, U.; Berger, R.; Olsson, M.; Grehk, T. M.; Sundell, P. E.; Johansson, M. "Bonding of vegetable oils to mercapto silane treated metal surfaces: Surface engineering on the nano scale", Thin Solid Films 2006, 515, 838-841.

126. Black, M.; Rawlins, J. W. "Thiol-ene UV-curable coatings using vegetable oil macromonomers", Eur. Polym. J. 2009, 45, 1433-1441.

127. Lluch, C.; Ronda, J. C.; Galià, M.; Lligadas, G.; Càdiz, V. "Rapid Approach to Biobased Telechelics through Two One-Pot Thiol-Ene Click Reactions", Biomacromolecules 2010, 11, 1646-1653.

128. Türünç, O.; Meier, M. A. R. "Fatty Acid Derived Monomers and Related Polymers Via Thiol-ene (Click) Additions", Macromol. Rapid Commun. 2010, 31, 1822-1826.

129. Lluch, C.; Lligadas, G.; Ronda, J. C.; Galià, M.; Cadiz, V. "“Click” Synthesis of Fatty Acid Derivatives as Fast-Degrading Polyanhydride Precursors", Macromol. Rapid Commun. 2011, n/a-n/a. 
130. Del Rio, E.; Lligadas, G.; Ronda, J. C.; Galià, M.; Cádiz, V. "Poly-2-oxazolinederived polyurethanes: A versatile synthetic approach to renewable polyurethane thermosets", J. Polym. Sci., Part A: Polym. Chem. 2011, 49, 3069-3079.

131. Desroches, M.; Caillol, S.; Lapinte, V.; Auvergne, R.; Boutevin, B. "Synthesis of Biobased Polyols by Thiol-Ene Coupling from Vegetable Oils", Macromolecules 2011, 44, 2489-2500.

132. Boutevin, B.; Caillol, S.; Desroches, M. "Procédé de fonctionnalisation de corps gras d'origine naturelle", FR1002738.

133. Desroches, M.; Boutevin, B.; Caillol, S.; Auvergne, R. "Synthesis of pseudo telechelic diols by trans-esterification and thiol-ene coupling from vegetable oil derivatives", Eur. J. Lipid Sci. Technol. 2011, accepted, DOI: 10.1002/ejlt.201100132.

134. Cramail, H.; Boyer, A.; Cloutet, E.; Alfos, C. "Novel method for preparing polyols by means of thiolation and products such as those obtained", WO 2011/045536 A1.

135. Stemmelen, M.; Pessel, F.; Lapinte, V.; Caillol, S.; Habas, J. P.; Robin, J. J. "A fully biobased epoxy resin from vegetable oils: From the synthesis of the precursors by thiol-ene reaction to the study of the final material", J. Polym. Sci., Part A: Polym. Chem. 2011, 49, 2434-2444.

136. Van der Steen, M.; Stevens, C. V. "Undecylenic Acid: A Valuable and Physiologically Active Renewable Building Block from Castor Oil", ChemSusChem 2009, 2, 692-713.

137. Ionescu, M.; Petrovic, Z. "Phenolation of vegetable oils", J. Serb. Chem. Soc. 2011, 76, 591-606.

138. Mol, J. C. "Catalytic Metathesis of Unsaturated Fatty Acid Esters and Oils", Top. Catal. 2004, 27, 97-104.

139. Mol, J. C. "Application of olefin metathesis in oleochemistry: an example of green chemistry", Green Chem. 2002, 4, 5-13.

140. Stempfle, F.; Quinzler, D.; Heckler, I.; Mecking, S. "Long-chain linear C19 and C23 monomers and polycondensatres from unsaturated fatty acid esters", Macromolecules 2011, 44, 4159-4166.

141. Schneider, M. P. "Plant-oil-based lubricants and hydraulic fluids", J. Sci. Food Agric. 2006, 86, 1769-1780.

142. O. Metzger, J. "Organic reactions without organic solvents and oils and fats as renewable raw materials for the chemical industry", Chemosphere 2001, 43, 8387.

143. Bondioli, P. "The Preparation of Fatty Acid Esters by Means of Catalytic Reactions", Top. Catal. 2004, 27, 77-82.

144. Srivastava, A.; Prasad, R. "Triglycerides-based diesel fuels", Renewable Sustainable Energy Rev. 2000, 4, 111-133.

145. Hartman, L. "Methanolysis of triglycerides", J. Am. Oil Chem. Soc. 1956, 33, 129.

146. Sendzikiene, E.; Makareviciene, V.; Janulis, P.; Kitrys, S. "Kinetics of free fatty acids esterification with methanol in the production of biodiesel fuel", Eur. J. Lipid Sci. Technol. 2004, 106, 831-836.

147. Marchetti, J. M.; Errazu, A. F. "Esterification of free fatty acids using sulfuric acid as catalyst in the presence of triglycerides", Biomass Bioenergy 2008, 32, 892-895. 
148. Takagaki, A.; Toda, M.; Okamura, M.; Kondo, J. N.; Hayashi, S.; Domen, K.; Hara, M. "Esterification of higher fatty acids by a novel strong solid acid", Catal. Today 2006, 116, 157-161.

149. Anton, A. K.; Alexandre, C. D.; Gadi, R. "Solid Acid Catalysts for Biodiesel Production --Towards Sustainable Energy", Adv. Synth. Catal. 2006, 348, 75-81.

150. Cardoso, A. L.; Neves, S. C. G.; da Silva, M. J. "Kinetic Study of Alcoholysis of the Fatty Acids Catalyzed by Tin Chloride(II): An Alternative Catalyst for Biodiesel Production", Energy \& Fuels 2009, 23, 1718-1722.

151. Hoshi, M.; Williams, M.; Kishimoto, Y. "Esterification of fatty acids at room temperature by chloroform-methanolic HCl-cupric acetate", J. Lipid Res. 1973, 14, 599-601.

152. Zilliken, F. W.; Egge, H. "Certain linoleic and linolenic acid ester fractions of vegetable oils and derivatives thereof", US 1972/3,676,472.

153. Lecocq, V.; Maury, S.; Bazer-Bachi, D. "Method for producing alcoholic esters from triglycerides and alcohols using heterogenous catalysts containing phosphate or an organophosphonated compound of a group 4 metal", WO 2008/135665 A1.

154. Desai, S. D.; Patel, J. V.; Sinha, V. K. "Polyurethane adhesive system from biomaterial-based polyol for bonding wood", Int. J. Adhes. Adhes. 2003, 23, 393-399.

155. Cramail, H.; Boyer, A.; Cloutet, E.; Alfos, C. "Novel castor oil derivatives and method for the production thereof", WO 2011/030075 A1.

156. Yeganeh, H.; Shamekhi, M. A. "Novel polyurethane insulating coatings based on polyhydroxyl compounds, derived from glycolysed PET and castor oil", $J$. Appl. Polym. Sci. 2006, 99, 1222-1233.

157. Petrović, Z. S.; Cvetković, I.; Hong, D.; Wan, X.; Zhang, W.; Abraham, T.; Malsam, J. "Polyester polyols and polyurethanes from ricinoleic acid", J. Appl. Polym. Sci. 2008, 108, 1184-1190.

158. Tanaka, R.; Hirose, S.; Hatakeyama, H. "Preparation and characterization of polyurethane foams using a palm oil-based polyol", Biores. Technol. 2008, 99, 3810-3816.

159. Dutta, N.; Karak, N.; Dolui, S. K. "Synthesis and characterization of polyester resins based on Nahar seed oil", Prog. Org. Coat. 2004, 49, 146-152.

160. Márquez-Alvarez, C.; Sastre, E.; Pérez-Pariente, J. "Solid Catalysts for the Synthesis of Fatty Esters of Glycerol, Polyglycerols and Sorbitol from Renewable Resources", Top. Catal. 2004, 27, 105-117.

161. Dutta, S.; Karak, N. "Effect of the NCO/OH ratio on the properties of Mesua Ferrea L. seed oil-modified polyurethane resins", Polym. Int. 2006, 55, 49-56.

162. Güner, F. S.; Baranak, M.; Soytas, S.; Erciyes, A. T. "Flow behavior of oilmodified polymer solutions", Prog. Org. Coat. 2004, 50, 172-178.

163. Uosukainen, E.; Linko, Y.-Y.; Lämsä, M.; Tervakangas, T.; Linko, P. "Transesterification of trimethylolpropane and rapeseed oil methyl ester to environmentally acceptable lubricants", J. Am. Oil Chem. Soc. 1998, 75, 15571563.

164. Linko, Y. Y.; Tervakangas, T.; Lämsä, M.; Linko, P. "Production of trimethylolpropane esters of rapeseed oil fatty acids by immobilized lipase", Biotechnol. Tech. 1997, 11, 889-892.

165. Törnvall, U.; Hatti-Kaul, R. "Specialty chemicals from vegetable oils: achievements within the Greenchem research program", Lipid Technol. 2007, 19, 84-87. 
166. Metzger, J.; Bornscheuer, U. "Lipids as renewable resources: current state of chemical and biotechnological conversion and diversification", Appl. Microbio. Biotech. 2006, 71, 13-22.

167. Somani, K. P.; Kansara, S. S.; Patel, N. K.; Rakshit, A. K. "Castor oil based polyurethane adhesives for wood-to-wood bonding", Int. J. Adhes. Adhes. 2003, 23, 269-275.

168. Wilson, R.; van Schie, B. J.; Howes, D. "Overview of the Preparation, Use and Biological Studies on Polyglycerol Polyricinoleate (PGPR)", Food Chem. Toxicol. 1998, 36, 711-718.

169. Lysenko, Z.; Schrock, A. K.; Babb, D. A.; Sanders, A.; Tsavals, J.; Jouett, R.; Chambers, L.; Keillor, C.; Gilchrist, J. H. "Vegetable oil based polyols and polyurethanes made therefrom", WO 2004/096882 A1.

170. Feairheller, S.; Bistline, R.; Bilyk, A.; Dudley, R.; Kozempel, M.; Haas, M. "A novel technique for the preparation of secondary fatty amides", J. Am. Oil Chem. Soc. 1994, 71, 863-866.

171. Martin, C. A.; Sanders, A.; Lysenko, Z.; Schrock, A. K.; Babb, D. A.; Earls, J. D.; Olson, K. D.; Briggs, J. R. "Polyurethanes made from hydroxyl-containing fatty acid amides", WO 2007/019063 A1.

172. Khoe, T.; Frankel, E. "Rigid polyurethane foams from diethanolamides of carboxylated oils and fatty acids", J. Am. Oil Chem. Soc. 1976, 53, 17-19.

173. Perella, J. E.; Komor, J. A.; Katstra, R. D. "Amphoteric derivatives of aliphatic polyamines with fatty acids, esters or triglycerides, which are useful for various consumer products and industrial applications", US 2002/6,369,007.

174. Rao, B. S.; Palanisamy, A. "Synthesis, photo curing and viscoelastic properties of triacrylate compositions based on ricinoleic acid amide derived from castor oil", Prog. Org. Coat. 2008, 63, 416-423.

175. Alam, M.; Alandis, N. "Development of Ambient Cured Polyesteramide Coatings from Linseed Oil: a Sustainable Resource", J. Polym. Environ. 2011, 19, 391-397.

176. Karol, T. J.; Sung, R. L. "Reaction product of beta-mercaptoethanol and coconut oil as diesel fuel antiwear additive", US 1986/4,566,878.

177. Rieke, R.; Thakur, D.; Roberts, B.; White, G. "Fatty methyl ester hydrogenation to fatty alcohol part I: Correlation between catalyst properties and activity/selectivity", J. Am. Oil Chem. Soc. 1997, 74, 333-339.

178. Gunstone, F. D. "Chemical reactions of fatty acids with special reference to the carboxyl group", Eur. J. Lipid Sci. Technol. 2001, 103, 307-314.

179. Nayak, U. R.; Deodhar, V. B.; Dalavoy, V. S. "Jasmonoids. Part 2. Two jasmonate-type cyclopentanone-based dimethyl esters from 10-undecenoic acid." Ind. J. Chem., Section B: Org. Chem. Med. Chem. 1989, 28B, 958-960.

180. Abraham, S.; Narine, S. S. "Polynonanolactone synthesized from vegetable oil: Evaluation of physical properties, biodegradation, and drug release behavior", $J$. Polym. Sci., Part A: Polym. Chem. 2009, 47, 6373-6387.

181. Liu, G.; Kong, X.; Wan, H.; Narine, S. "Production of 9-Hydroxynonanoic Acid from Methyl Oleate and Conversion into Lactone Monomers for the Synthesis of Biodegradable Polylactones", Biomacromolecules 2008, 9, 949-953.

182. Palaskar, D. V.; Boyer, A. 1.; Cloutet, E.; Alfos, C.; Cramail, H. "Synthesis of Biobased Polyurethane from Oleic and Ricinoleic Acids as the Renewable Resources via the AB-Type Self-Condensation Approach", Biomacromolecules 2010, 11, 1202-1211. 
183. Cramail, H.; Boyer, A.; Palaskar, D. V.; Cloutet, E.; Alfos, C. "Polyurethane synthesis by means of self condensation", WO 2011/045546 A2.

184. Cervin, M.; Soucaille, P.; Valle, F. "Process for the biological production of 1,3propanediol with high yield", WO 2004/033646 A2.

185. Sunkara, H. B.; Ng, H. C. "Polytrimethylene ether glycol with excellent quality from biochemically derived 1,3-propanediol", WO 2004/101469 A2.

186. Zhao, H.; Herrington, R.; Driguez, F. "Natural oil based autocatalytic polyols", WO 2010/008675 A1.

187. Casper, D. M.; Newbold, T. "Method for preparing hydroxy functional vegetable oils", US 2006/0,041,156 A1.

188. Luo, N.; Newbold, T. "A process for the manufacture of natural oil hydroxylates", WO 2008/130646 A1.

189. Herrington, R.; Malsam, J. "Flexible polyurethane foams prepared using modified vegetable oil based polyols", WO 2005/033167 A1.

190. Petrovic, Z. S. "Modified vegetable oil-based polyols", US 2010/0311992 A1.

191. Hellbardt, S.; Zech, W.; Schlandt, K. "Verfahren zur herstellung hydroxylierter fettsäureverbindungen (Process for the preparation of compounds of hydroxylated fatty acid", EP 1993 / 0554590 A2.

192. Metivier, P.; Dos Santos, E. "Procédés de préparation d'acides mono et dicarboxyliques à partir d'acides gras insaturés et/ou leurs dérivés", FR 2724651 A1.

193. Metivier, P. "Préparation de dérivés d'acides gras monocarboxyles portant deux fonctions hydroxyles vicinales ou une fonction époxyde", FR 2789013 A1.

194. Metivier, P. "Procédés d'époxydation ou de dihydroxylation d'acides gras insaturés", WO 2000/44704.

195. Hsiao, Y. L. "Polyurethane foams made with alcoxylated vegetable oil hydroxylate", US 2006/0229375 A1.

196. Lorenz, K. "Process for the production of polyols based on natural oils", US 2007/0,123,725 A1.

197. Lysenko, Z. "Vegetable oil based polyols and polyurethanes made therefrom", WO 2004/096882 A1.

198. Mijolovic, D. "Process for preparing polyether alcohols", US 2010/0,298,460 A1.

199. Hill, K. "Fats and oils as oleochemical raw materials", Pure Appl. Chem. 2000, $72,1255-1264$.

200. Kurth, T. M.; Kurth, R. A.; Turner, R. B.; Kreifels, L. P. "Oxylated vegetablebased polyol having increased functionality and urethane materials formed using the polyol", US 2004/0209971 A1.

201. Blease, T. G. "Dispersions of a solid in an aqueous liquid including a polyalkyleneglycol ester or amide of a fatty acid dimer and/or trimer", WO 2003/106010 A1.

202. Cameron, P.; Appleman, E. "Polyurethane foam", US 2010/0,112,333 A1.

203. Nozawa, K.; Sasaki, M.; K., O. "Composition for polyurethane foam, polyurethane foam obtained from the composition, and use thereof", US 2009/0,127,915.

204. 1. D. Reed, Urethanes Technology, 2000, 17, 4, 41.

205. M. Szycher, Szycher's Handbook of Polyurethanes, CRC Press, Boca Raton, FL, USA, 1999, Chapter 2, p.7, Chapter 3, p.10, Chapter 5, p.4-6.

206. Regulations $\mathbf{1 9 0 7 / 2 0 0 6 / C E}$ and 2006/121/CE 
Table 1: Mains reactions used on vegetable oils

Table 2: Properties of commercial polyols from vegetable oils epoxidation

Table 3: properties of commercial polyols from various reactions on vegetable oils

Scheme 1: Polyurethane synthesis from diol and diisocyanate

Scheme 2: Triglyceride formula with R0, R1 and R3 aliphatic chains of fatty acids

Scheme 3: Triglyceride formula with $\mathrm{R}_{0}$ chain corresponding to oleic acid

Scheme 4: Synthesis of epoxidized triglycerides

Scheme 5: In situ triglyceride epoxide ring opening

Scheme 6: Triglycerides epoxide ring opening by methanol

Scheme 7: Synthesis of primary terminal alcohols from triolein for polyurethanes formulation

Scheme 8: Epoxide ring opening polymerization of epoxidized methyl oleate

Scheme 9: Triglyceride epoxide ring opening with butane-1-thiol

Scheme 10: Oxirane ring opening with diethylamine

Scheme 11: Triglyceride epoxide ring opening with acrylic acid

Scheme 12: Direct hydrogenation of triglyceride epoxides

Scheme 13: Triglyceride epoxide ring opening by ethan-1,2-diol

Scheme 14: Competitive reactions occurring during triglyceride amidification by diethanolamine

Scheme 15: Triglyceride epoxide ring opening with lactic acid

Scheme 16: Polyols synthesis from carbonated oil

Scheme 17: Summary of most common functionalizations on epoxidized vegetable oils 
Scheme 18: Ozonolysis of unsaturated triglycerides leading to terminal primary hydroxyl functions

Scheme 19: Allyl hydroperoxides synthesis then converted into enone groups or reduced into secondary alcohols

Scheme 20: Hydroformylation followed by reduction on unsaturated triglyceride

Scheme 21: Hydroaminomethylation of ethyl oleate by valinol (dioxane, $140^{\circ} \mathrm{C}, 20 \mathrm{~h}$, rhodium complex catalyst, yield 95\%)

Scheme 22: Fatty acid dimer (left hand) and fatty diol dimer (right hand)

Scheme 23: Dimerization reaction of conjugated linoleic acid

Scheme 24: Dimerization reaction of oleic acid

Scheme 25: Aromatic triols synthesis from (a) methyl-9-octadecenoate and (b) methyl10-undecenoate

Scheme 26: Mechanism of thiol-ene coupling

Scheme 27: Fatty ester trimerization by thiol-ene coupling

Scheme 28: Synthesis of the poly-2-oxazoline polyols from 10-undecenoic and decanoic acid

Scheme 29: Products and by-products of thiol-ene coupling of 2-mercaptoethanol on fatty acid

Scheme 30: Formaldehyde addition onto fatty acid

Scheme 31: Undecylenic acid acylation

Scheme 32: Linear diols from unsaturated fatty esters alkoxycarbonylation

Scheme 33: Double bond modifications for the synthesis of polyols from vegetable oils and derivatives

Scheme 34: Transesterification reaction of a triglyceride with glycerin 
Scheme 35: Esterification reaction on fatty acid

Scheme 36: Self condensation of fatty acids

Scheme 37: Synthesis of unsaturated amides by amidification/esterification

Scheme 38: Thioesterification of triglyceride with 2-mercaptoethanol

Scheme 39: Surfactant synthesis from fatty alcohols

Scheme 40: Synthesis of $\gamma$-stearolactone

Scheme 41: Synthesis of hydroxylesters or hydroxylamides from $\delta$-lactones

Scheme 42: Synthesis of polynonanolactones

Scheme 43: Synthesis of $A B$ monomer for polyurethanes synthesis by direct polycondensation

Scheme 44: Summary of various products obtained by functionalization of ester group of vegetable oils and derivatives

Scheme 45: Summary of various products obtained from biomass

Scheme 46: Structure of Lupranol® Balance 50 polyol 


\begin{tabular}{|c|c|c|}
\hline Reaction & Name & Scheme \\
\hline $\mathbf{A}$ & Epoxidation & $\longrightarrow \mathrm{R}_{1} \underset{\mathrm{R}_{2}}{\mathrm{O}} \underset{\mathrm{R}_{4}}{\longrightarrow} \mathrm{R}_{3}$ \\
\hline B & $\begin{array}{l}\text { Epoxide ring } \\
\text { opening }\end{array}$ & 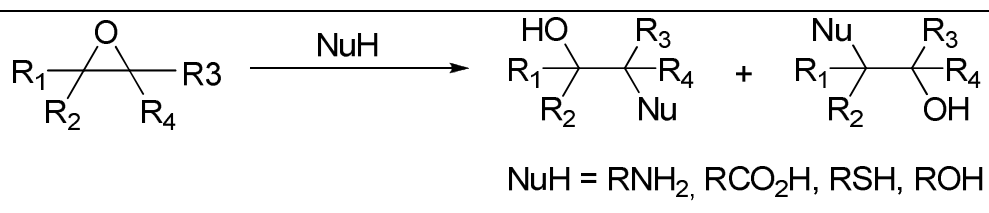 \\
\hline C & $\begin{array}{l}\text { Epoxides } \\
\text { hydrogenation }\end{array}$ & 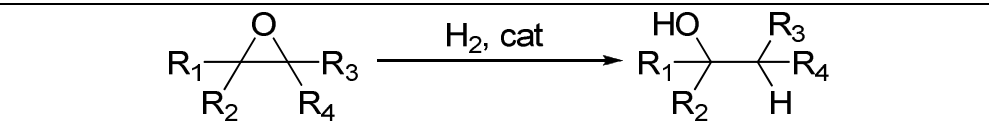 \\
\hline D & $\begin{array}{l}\text { Ozonolysis - } \\
\text { hydrogenation }\end{array}$ & $\stackrel{\mathrm{R}_{2}}{\mathrm{R}_{1}}=\langle_{\mathrm{R}_{4}}^{\mathrm{R}_{3}} \stackrel{\mathrm{O}_{3}}{\mathrm{H}_{2} \text {, cat }} \underset{\mathrm{R}_{1}}{\lambda_{\mathrm{R}_{2}}^{\mathrm{OH}}}+{ }_{\mathrm{R}_{3}} \overbrace{\mathrm{R}_{4}}^{\mathrm{OH}}$ \\
\hline $\mathbf{E}$ & $\begin{array}{l}\text { Hydro } \\
\text { formylation }\end{array}$ & $\underset{R_{1}}{\mathrm{R}_{2}} \underset{\mathrm{R}_{4}}{\mathrm{O}} \mathrm{R}_{3} \stackrel{\mathrm{CO}, \mathrm{H}_{2} \text {, cat }}{\longrightarrow} \mathrm{R}_{\mathrm{HO}}^{\mathrm{R}_{1}} y_{\mathrm{R}_{4}}^{\mathrm{R}_{2}}$ \\
\hline $\mathbf{F}$ & $\begin{array}{l}\text { Thiol-ene } \\
\text { coupling }\end{array}$ & $\stackrel{\mathrm{R}_{5} \mathrm{SH}}{\longrightarrow} \underset{\substack{\mathrm{R}_{2} \\
\mathrm{R}_{5} \mathrm{~S}}}{\mathrm{R}_{1}} \mathrm{R}_{\mathrm{R}_{4}}^{\mathrm{R}_{3}}$ \\
\hline G & Oxidation & 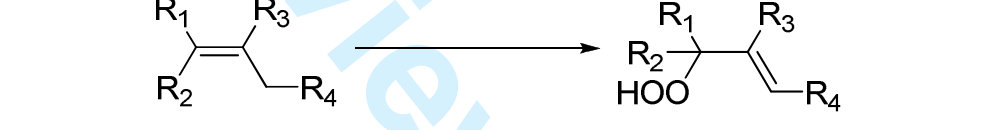 \\
\hline $\mathbf{H}$ & Reduction & $\mathrm{R}_{1}-\mathrm{O}_{\mathrm{O}-\mathrm{R}_{2}}^{\mathrm{O}}$ \\
\hline $\mathbf{I}$ & $\begin{array}{l}\text { (Trans) } \\
\text { esterification }\end{array}$ & $\mathrm{R}_{1}-\mathrm{O}_{\mathrm{O}-\mathrm{R}_{2}}^{\mathrm{O}} \stackrel{\mathrm{R}_{3} \mathrm{OH}}{\longrightarrow} \mathrm{R}_{1}-\mathrm{O}_{\mathrm{O}-\mathrm{R}_{3}}^{\mathrm{O}}+\mathrm{R}_{2} \mathrm{OH}$ \\
\hline $\mathbf{J}$ & Amidification & 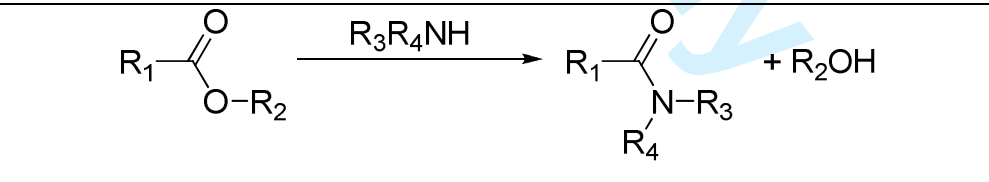 \\
\hline $\mathbf{K}$ & $\begin{array}{l}\text { Diels Alder } \\
\text { cyclization }\end{array}$ & $\mathrm{R}_{2}^{\mathrm{R}_{1}}+\prod_{\mathrm{R}_{3}}^{\mathrm{L}}-$ \\
\hline
\end{tabular}

URL: http://mc.manuscriptcentral.com/LMSC Email: polyreviews@bellsouth.net 


1
1
3
4
5
6
7
8
9
10
11
12
13
14
15
16
17
18
19
20
21
22
23
24
25
26
27
28
29
30
31
32
33
34
35
36
37
38
39
40
41
42
43
44
55
50
56
57
48
59
50
51
53
50

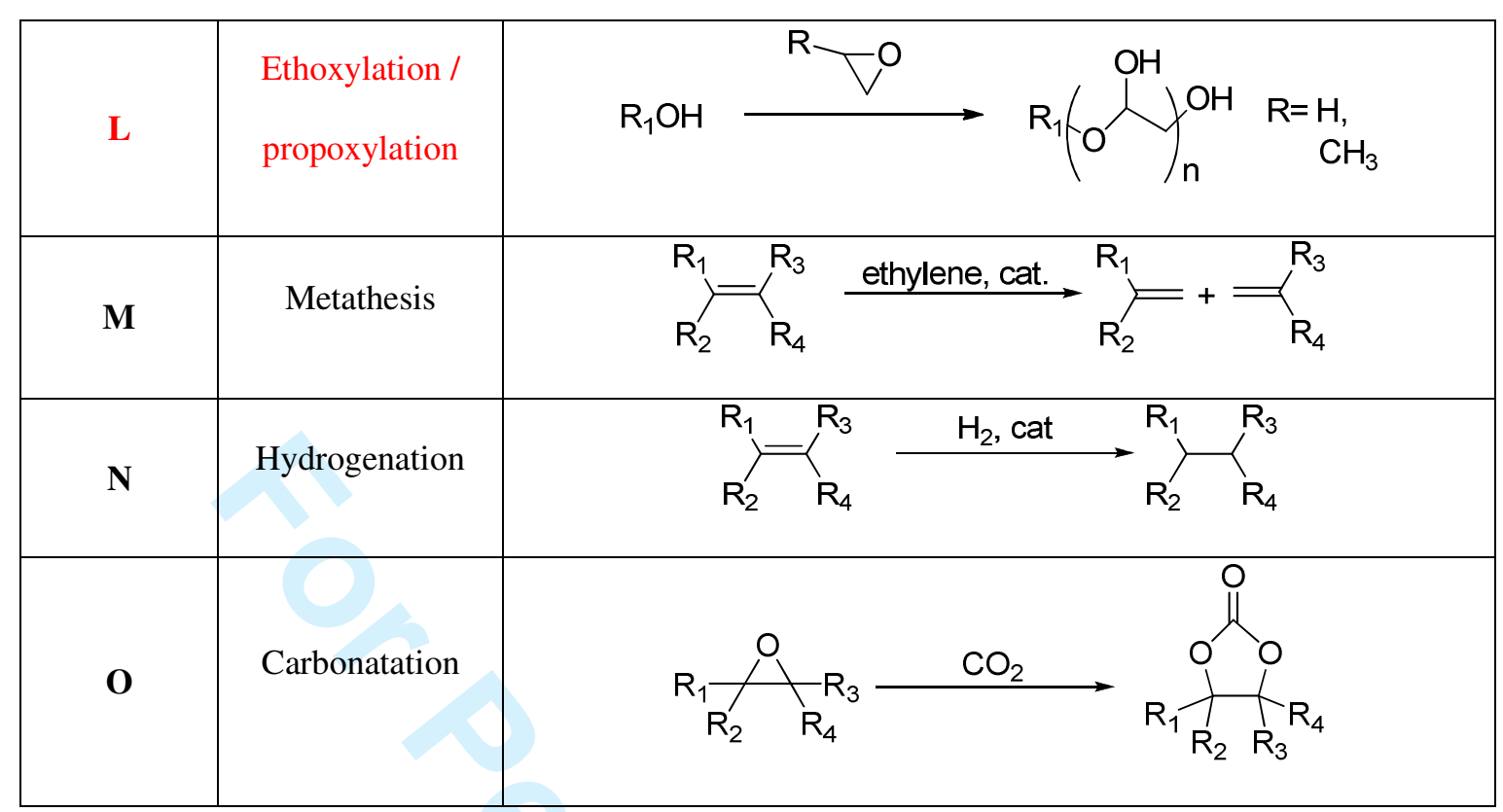

URL: http://mc.manuscriptcentral.com/LMSC Email: polyreviews@bellsouth.net 


\begin{tabular}{|c|c|c|c|c|c|c|}
\hline Company & $\begin{array}{c}\text { Commercial } \\
\text { product }\end{array}$ & $\begin{array}{c}\mathrm{I}_{\mathrm{OH}}(\mathrm{mg} \\
\mathrm{KOH} / \mathrm{g})\end{array}$ & $\mathrm{I}_{\mathrm{a}}(\mathrm{mg} \mathrm{KOH} / \mathrm{g})$ & $\begin{array}{l}\text { Density } \\
\left(\mathrm{g} / \mathrm{cm}^{3}\right)\end{array}$ & $\begin{array}{c}\text { Viscosity } \\
\text { (cP) }\end{array}$ & $\mathbf{f}$ \\
\hline HUNTSMAN & Jeffadd B650 & 650 & 0 & 1.080 & 30000 & - \\
\hline & Agrol 2.0 & $65-75$ & $<1$ & 0.955 & 230 & 2.0 \\
\hline & Agrol 3.6 & $107-117$ & $<1$ & 0.975 & 720 & 3.6 \\
\hline BIOBASED & Agrol 4.3 & $125-137$ & $<1$ & 0.976 & 1320 & 4.3 \\
\hline \multirow[t]{3}{*}{ TECH } & Agrol 5.6 & $151-170$ & $<1$ & 0.994 & 4770 & 5.6 \\
\hline & Agrol 7.0 & $175-195$ & $<1$ & 1.023 & 21500 & 7.0 \\
\hline & Agrol Diamond & $320-350$ & $<1$ & 1.017 & 3400 & 3.0 \\
\hline \multirow{2}{*}{ CARGILL } & $\mathrm{BiOH} \mathrm{X-0500}$ & 56 & 0.3 & 1.000 & 4500 & 2.0 \\
\hline & $\mathrm{BiOH} \mathrm{X-0210}$ & 235 & 1.7 & 1.010 & 8900 & 4.4 \\
\hline BASF & Sovermol 320 & $300-320$ & $<6$ & - & $800-1200$ & 2.8 \\
\hline \multirow[t]{15}{*}{ (COGNIS) } & Sovermol 650 & $186-206$ & $0-1$ & $0.91-0.92$ & $3700-4600$ & 2.2 \\
\hline & Sovermol 750 & $300-330$ & $<2$ & $0.98-1.02$ & $700-1400$ & 3.0 \\
\hline & Sovermol 760 & $370-410$ & $<2$ & $1-1.04$ & $1500-3000$ & 3.5 \\
\hline & Sovermol 805 & $160-185$ & $<3$ & $0.98-1.02$ & $2800-4000$ & 3.5 \\
\hline & Sovermol 810 & $220-240$ & $<3$ & - & $700-1100$ & 3.3 \\
\hline & Sovermol 815 & $200-230$ & $<3$ & $0.98-1.02$ & $1300-1900$ & 3.3 \\
\hline & Sovermol 818 & $223-248$ & $<3$ & $0.975-1.02$ & $650-850$ & 2.6 \\
\hline & Sovermol 819 & $230-250$ & $>3$ & $0.96-1.02$ & $750-950$ & 2.6 \\
\hline & Sovermol 860 & $190-220$ & $<1.5$ & $0.98-1.02$ & $200-650$ & 2.5 \\
\hline & Sovermol 908 & $200-212$ & $<0.2$ & - & $1800-2800$ & 2.0 \\
\hline & Sovermol 1005 & $117-130$ & $<3$ & $0.94-0.96$ & $600-900$ & 2.2 \\
\hline & Sovermol 1014 & $155-168$ & $<4$ & - & $600-800$ & 2.5 \\
\hline & Sovermol 1055 & $180-190$ & $<1$ & $0.90-0.91$ & $10-20$ & - \\
\hline & Sovermol 1058 & $180-200$ & $<1$ & $0.87-0.89$ & $0-15$ & - \\
\hline & Sovermol 1083 & $160-180$ & $<3$ & $0.98-1.02$ & $1800-2500$ & 3.3 \\
\hline
\end{tabular}




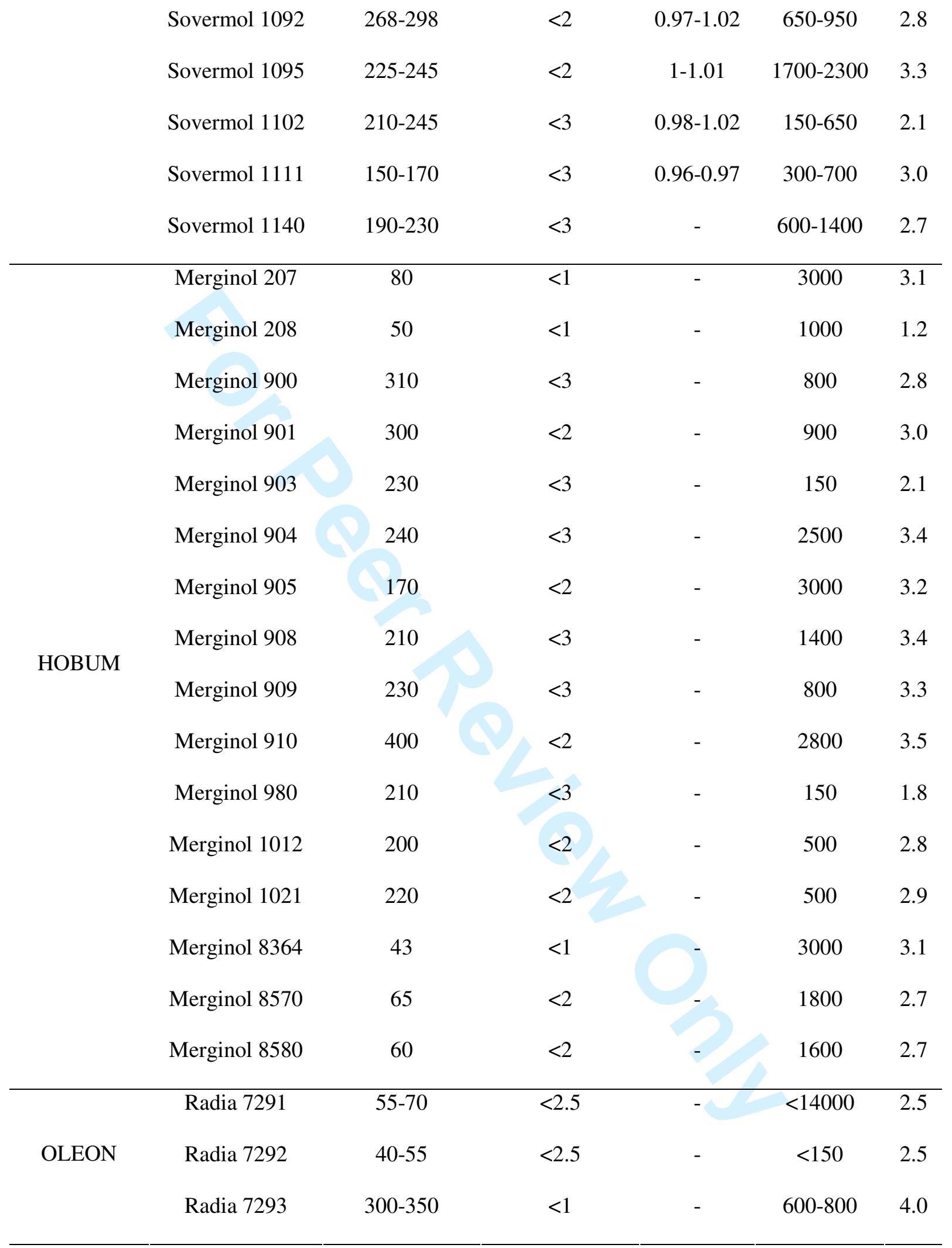




\begin{tabular}{|c|c|c|c|c|}
\hline Company & $\begin{array}{c}\text { Commercial } \\
\text { product }\end{array}$ & $\mathrm{I}_{\mathrm{OH}}(\mathrm{mg} \mathrm{KOH} / \mathrm{g})$ & $\mathrm{I}_{\mathrm{a}}(\mathrm{mg} \mathrm{KOH} / \mathrm{g})$ & Viscosity (cP) \\
\hline BASF & Lupranol balance 50 & 50 & $<0.06$ & 725 \\
\hline \multirow{5}{*}{ Urethane Sos } & Soyol 1001 & $53-60$ & $3-5$ & $800-1500$ \\
\hline & Soyol 2001 & $60-80$ & $<5$ & $1200-2500$ \\
\hline & Soyol 2101 & $55-70$ & $<3$ & $1500-3000$ \\
\hline & Soyol 2102 & $55-70$ & $<3$ & $1500-3000$ \\
\hline & Soyol 2999 & $55-70$ & $<1.5$ & $1500-3000$ \\
\hline \multirow{2}{*}{ Croda } & Priplast 1838 & 60 & 0.3 & - \\
\hline & Priplast 3196 & 39 & 0.3 & 40020 \\
\hline \multirow{3}{*}{ Cognis } & Sovermol 110 & $625-645$ & - & Solid at $25^{\circ} \mathrm{C}$ \\
\hline & Sovermol 909/910 & $90-112 / 50-60$ & - & Solid at $25^{\circ} \mathrm{C}$ \\
\hline & Sovermol 908 & $180-210$ & - & $1800-2800$ \\
\hline
\end{tabular}




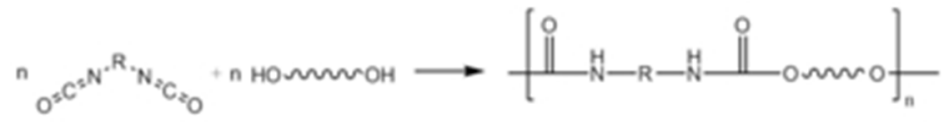

$30 \times 22 \mathrm{~mm}(300 \times 300 \mathrm{DPI})$

URL: http://mc.manuscriptcentral.com/LMSC Email: polyreviews@bellsouth.net 


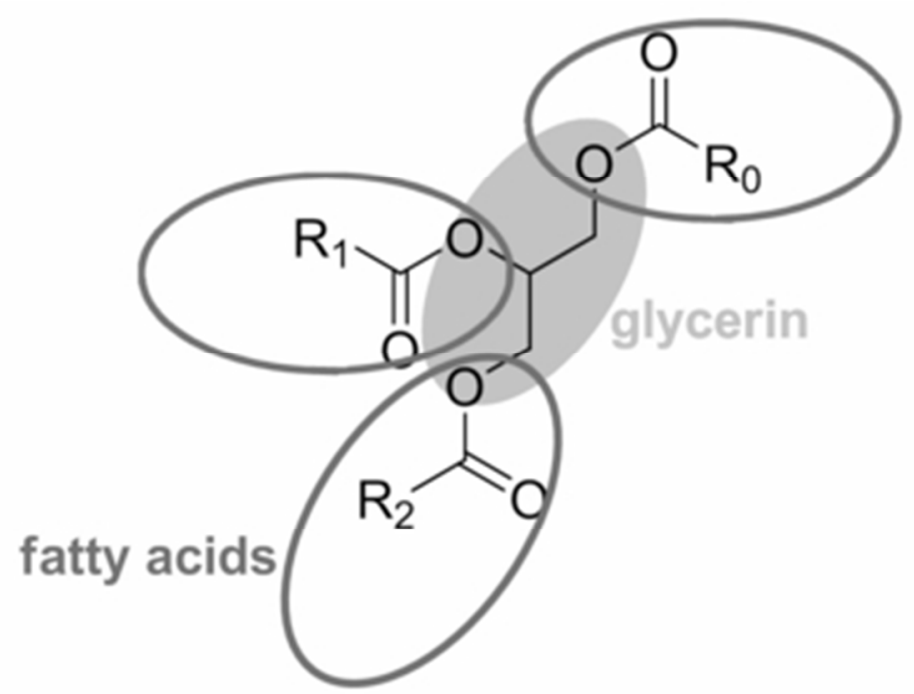

$30 \times 22 \mathrm{~mm}(300 \times 300$ DPI $)$

1
2
3
4
5
6
7
8
9
10
11
12
13
14
15
16
17
18
19
20
21
22
23
24
25
26
27
28
29
30
31
32
33
34
35
36
37
38
39
40
41
42
43
44
45
46
47
48
49
50
51
52
53
54
55
56
57
58
59
60




1
2
3
4
5
6
7
8
9
10
11
12
13
14
15
16
17
18
19
20
21
22
23
24
25
26
27
28
29
30
31
32
33
34
35
36
37
38
39
40
41
42
43
44
45
46
47
48
49
50
51
52
53
54
55
56
57
50

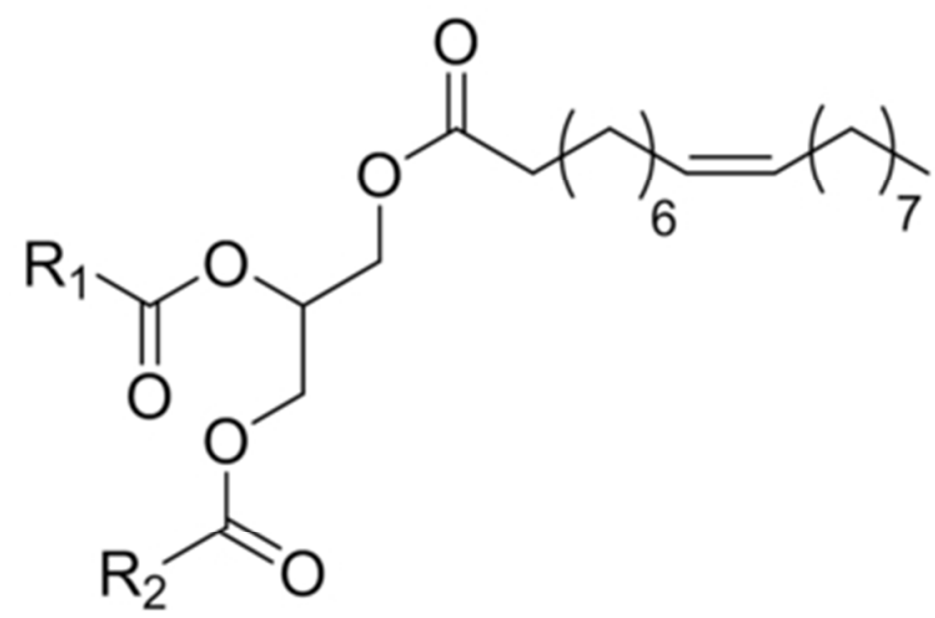

$30 \times 22 \mathrm{~mm}(300 \times 300 \mathrm{DPI})$

URL: http://mc.manuscriptcentral.com/LMSC Email: polyreviews@bellsouth.net 


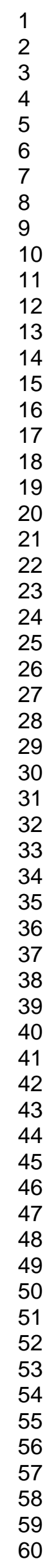

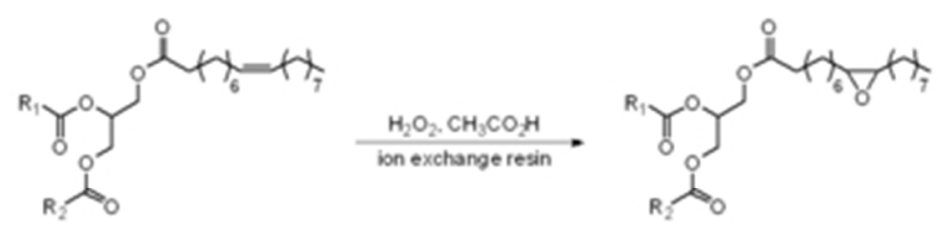

$30 \times 22 \mathrm{~mm}(300 \times 300 \mathrm{DPI})$

URL: http://mc.manuscriptcentral.com/LMSC Email: polyreviews@bellsouth.net 


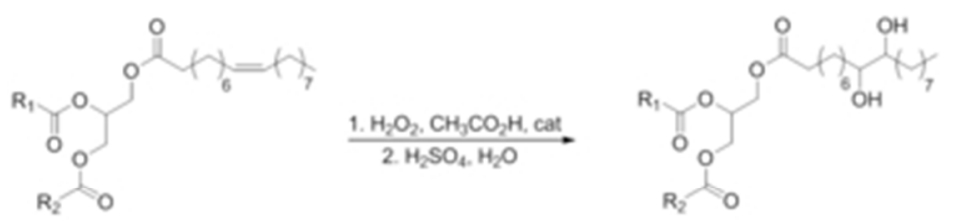

$30 \times 22 \mathrm{~mm}(300 \times 300 \mathrm{DPI})$

URL: http://mc.manuscriptcentral.com/LMSC Email: polyreviews@bellsouth.net 


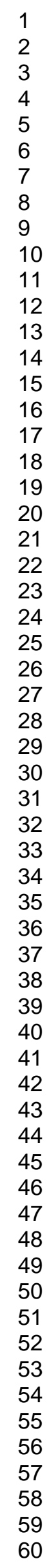

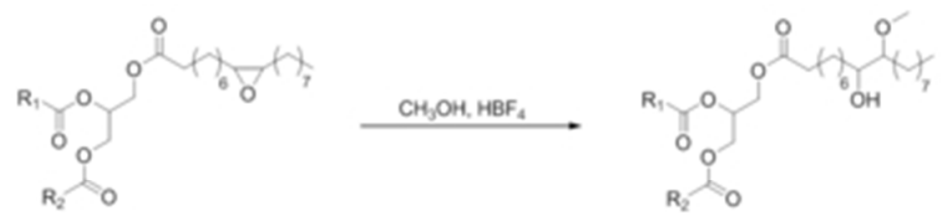

$30 \times 22 \mathrm{~mm}(300 \times 300 \mathrm{DPI})$

URL: http://mc.manuscriptcentral.com/LMSC Email: polyreviews@bellsouth.net 

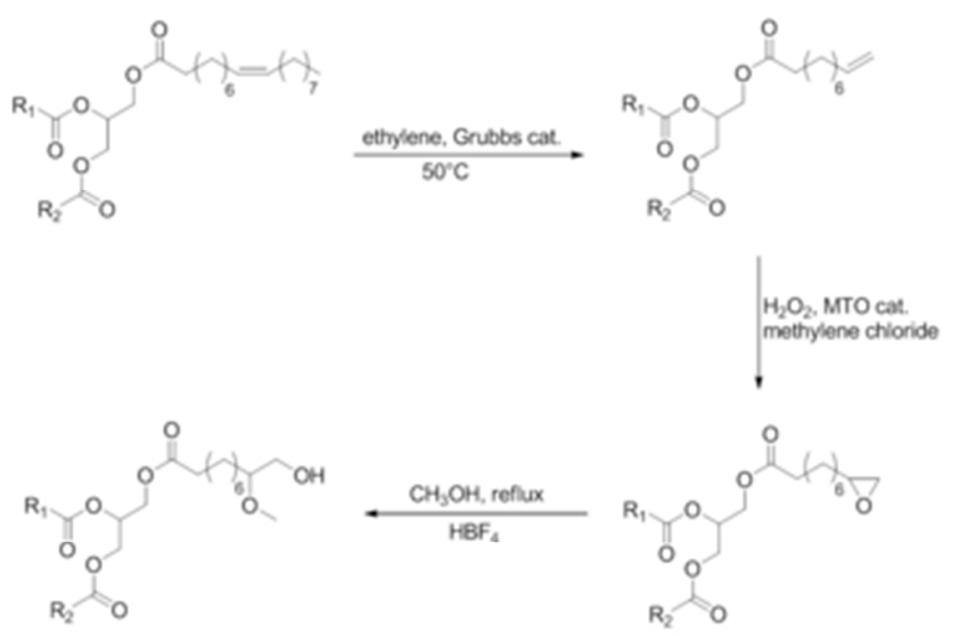

$30 \times 22 \mathrm{~mm}(300 \times 300 \mathrm{DPI})$

URL: http://mc.manuscriptcentral.com/LMSC Email: polyreviews@bellsouth.net 


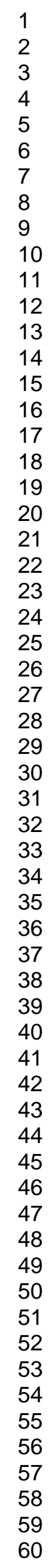
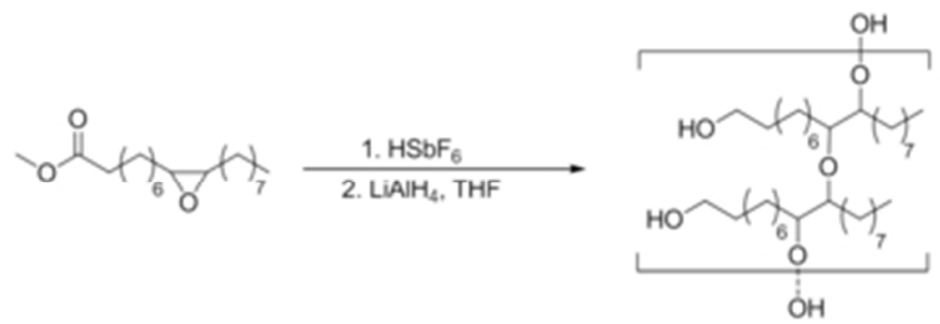

$30 \times 22 \mathrm{~mm}(300 \times 300$ DPI $)$

29

32

33

34

35

36

39

40

41

42

44

45

46

47

48

49

51

52

53

54

56

57

58

59

60

URL: http://mc.manuscriptcentral.com/LMSC Email: polyreviews@bellsouth.net 


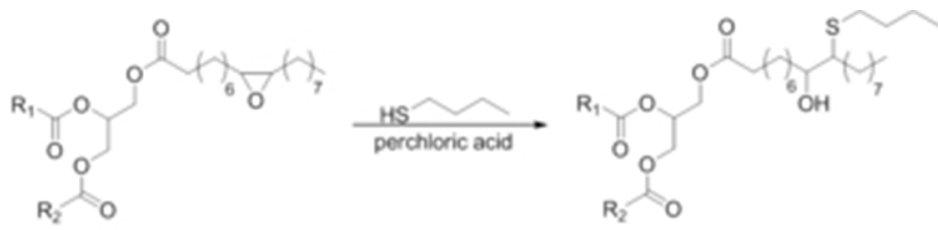

$30 \times 22 \mathrm{~mm}(300 \times 300$ DPI $)$

29

30

32

33

34

35

36

39

40

41

42

44

45

46

47

48

49

51

52

53

54

55

57

58

59

60

URL: http://mc.manuscriptcentral.com/LMSC Email: polyreviews@bellsouth.net 


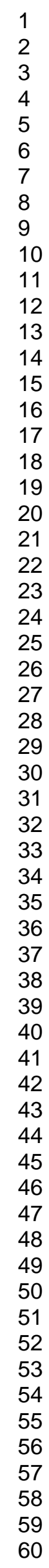

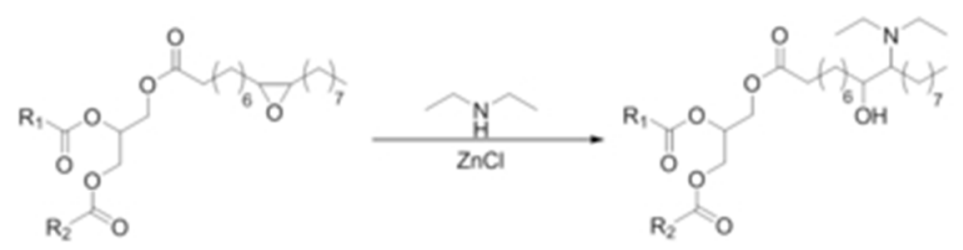

$30 \times 22 \mathrm{~mm}(300 \times 300 \mathrm{DPI})$

URL: http://mc.manuscriptcentral.com/LMSC Email: polyreviews@bellsouth.net 


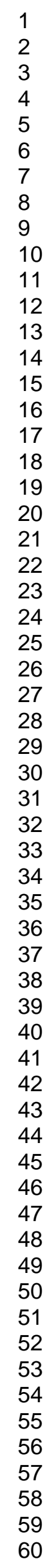

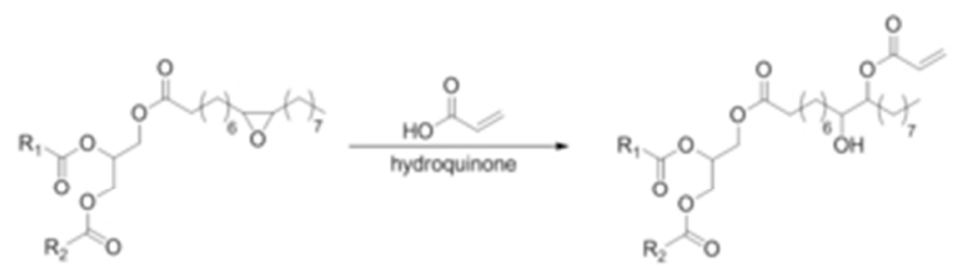

$30 \times 22 \mathrm{~mm}(300 \times 300 \mathrm{DPI})$

URL: http://mc.manuscriptcentral.com/LMSC Email: polyreviews@bellsouth.net 


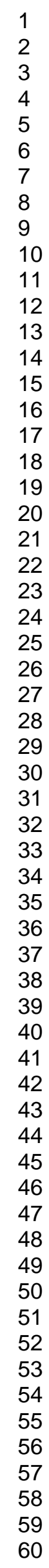

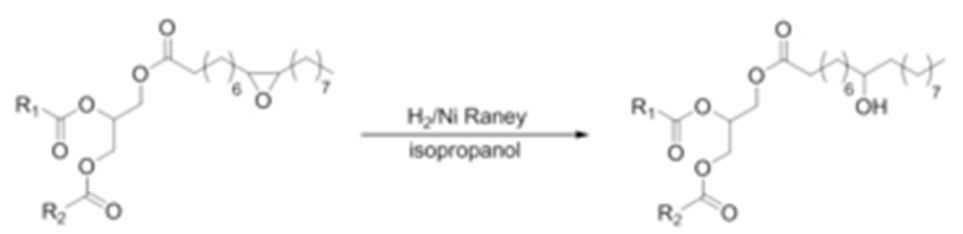

$30 \times 22 \mathrm{~mm}(300 \times 300 \mathrm{DPI})$

URL: http://mc.manuscriptcentral.com/LMSC Email: polyreviews@bellsouth.net 


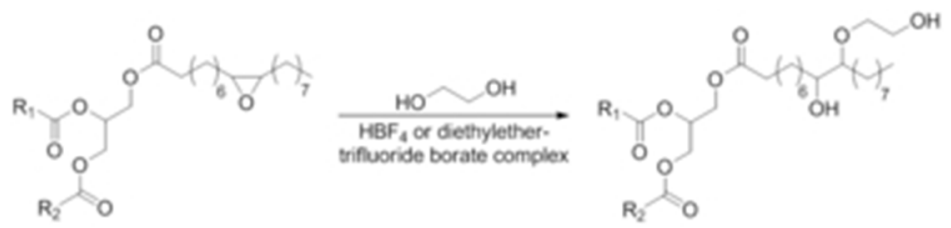

$30 \times 22 \mathrm{~mm}(300 \times 300 \mathrm{DPI})$

URL: http://mc.manuscriptcentral.com/LMSC Email: polyreviews@bellsouth.net 


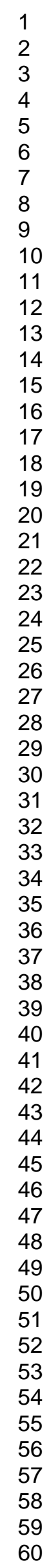

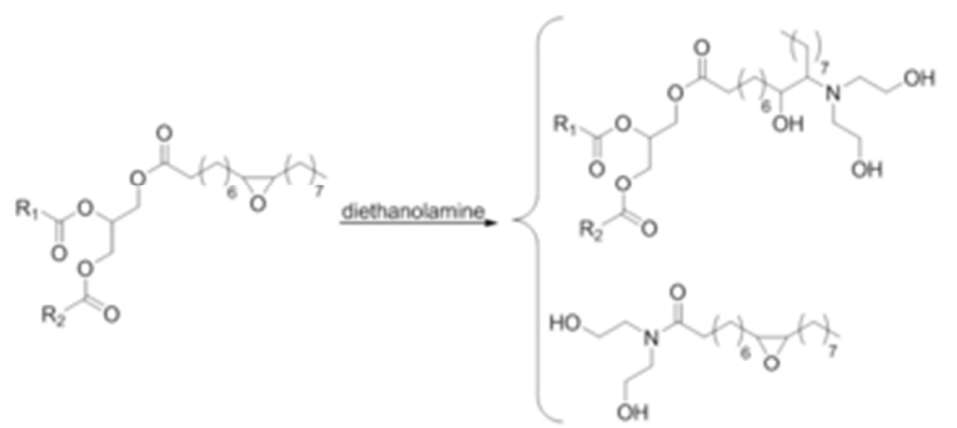

$30 \times 22 \mathrm{~mm}(300 \times 300 \mathrm{DPI})$

URL: http://mc.manuscriptcentral.com/LMSC Email: polyreviews@bellsouth.net 


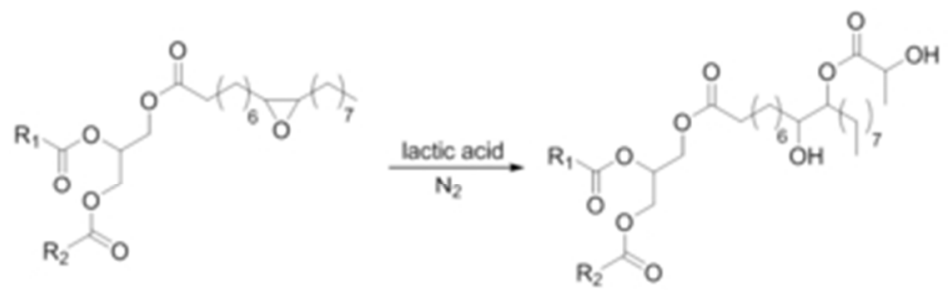

$30 \times 22 \mathrm{~mm}(300 \times 300 \mathrm{DPI})$

29

32

33

34

36

37

38

39

40

41

42
43

44

45

46

47

48

49

51

52

53

54

55

57

58

59

60

URL: http://mc.manuscriptcentral.com/LMSC Email: polyreviews@bellsouth.net 


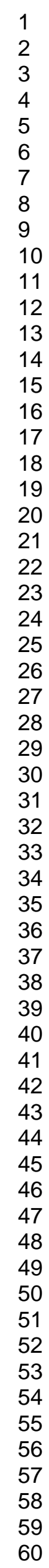

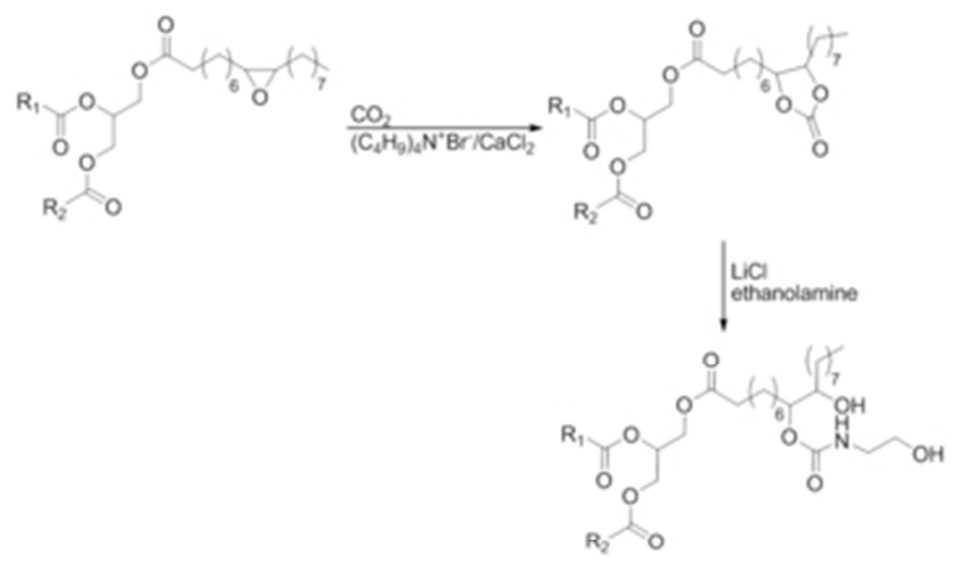

$30 \times 22 \mathrm{~mm}(300 \times 300 \mathrm{DPI})$

URL: http://mc.manuscriptcentral.com/LMSC Email: polyreviews@bellsouth.net 


1
1
3
4
5
6
7
8
9
10
11
12
13
14
15
16
17
18
19
20
21
22
23
24
25
26
27
28
29
30
31
32
33
34
35
36
37
38
39
40
41
42
43
44
55
50
56
57
48
59
50
51
53
50

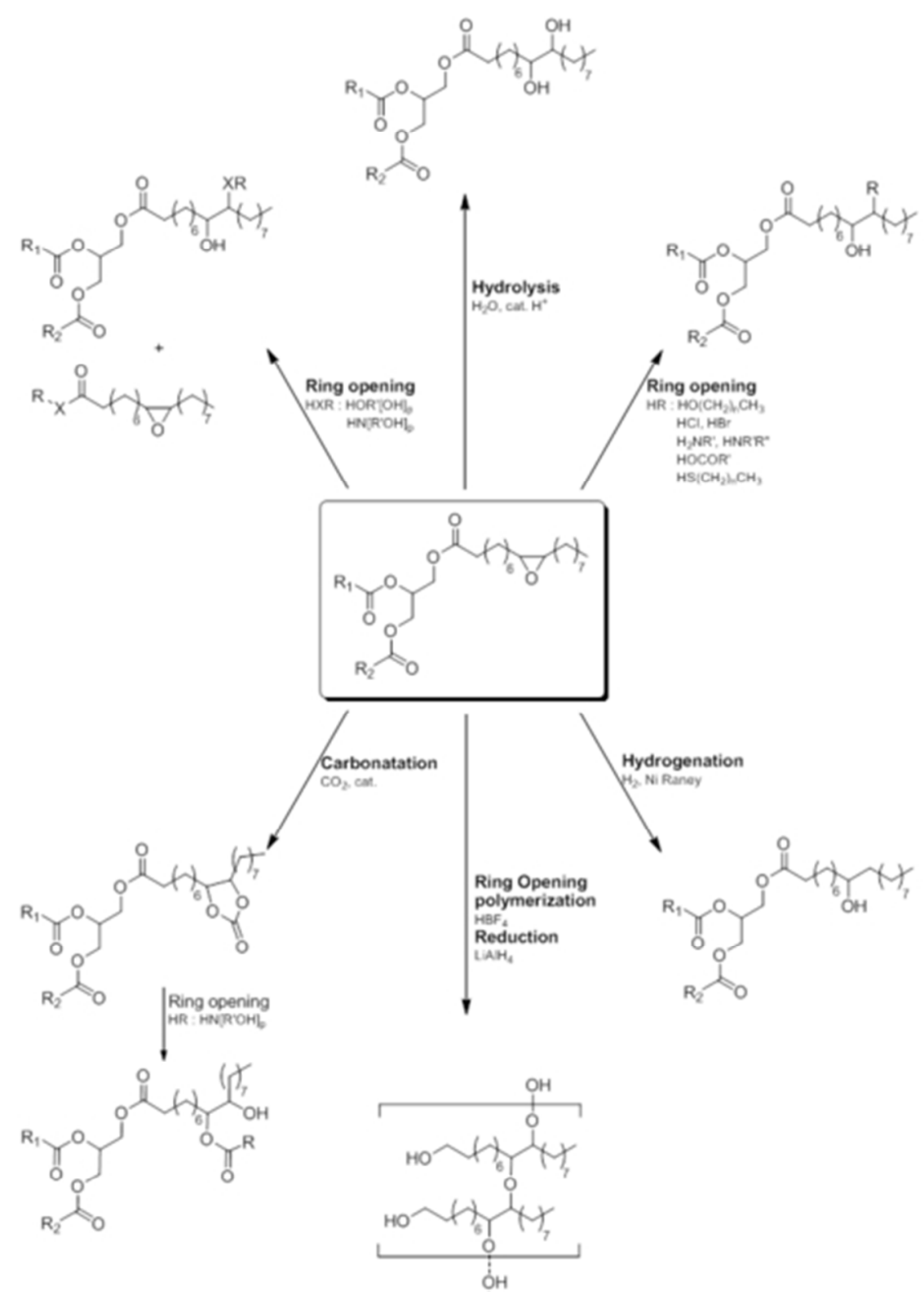

$40 \times 54 \mathrm{~mm}(300 \times 300$ DPI $)$

URL: http://mc.manuscriptcentral.com/LMSC Email: polyreviews@bellsouth.net 


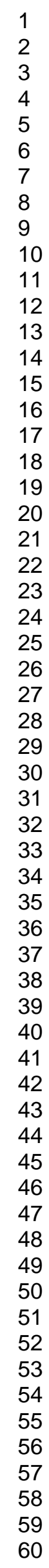

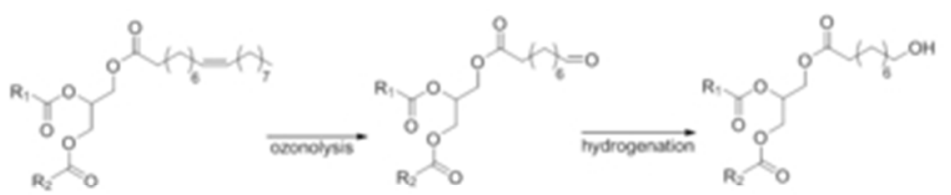

$30 \times 22 \mathrm{~mm}(300 \times 300 \mathrm{DPI})$

URL: http://mc.manuscriptcentral.com/LMSC Email: polyreviews@bellsouth.net 

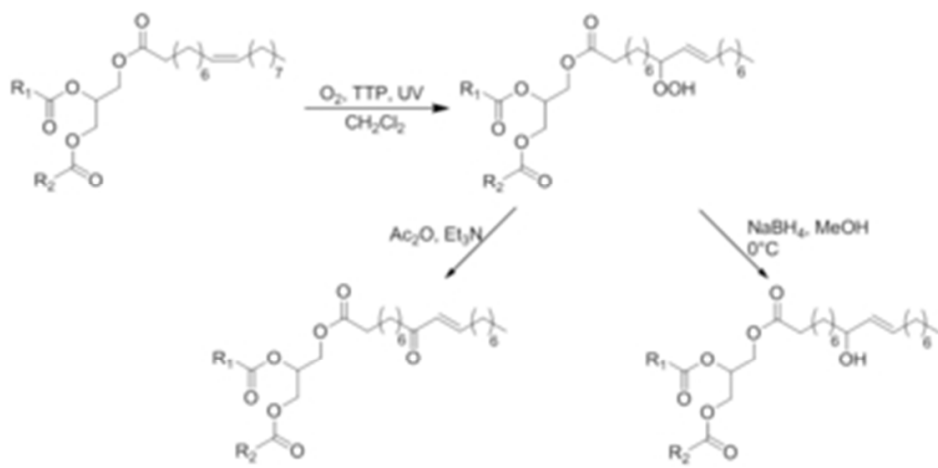

$30 \times 22 \mathrm{~mm}(300 \times 300 \mathrm{DPI})$ 


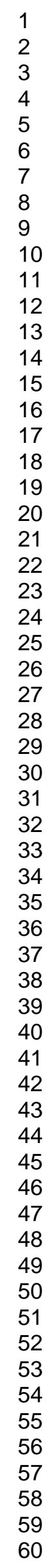

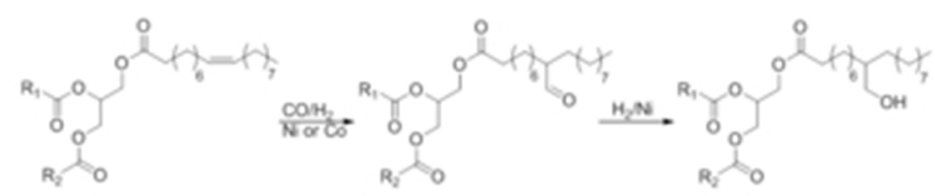

$30 \times 22 \mathrm{~mm}(300 \times 300 \mathrm{DPI})$

URL: http://mc.manuscriptcentral.com/LMSC Email: polyreviews@bellsouth.net 


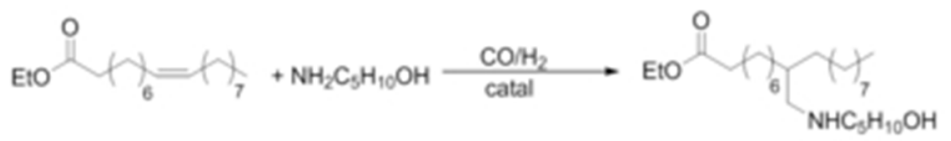

$30 \times 22 \mathrm{~mm}(300 \times 300 \mathrm{DPI})$

29

32

33

34

36

39

40

41

42

44

45

46

47

48

49

51

52

53

54

55

56 


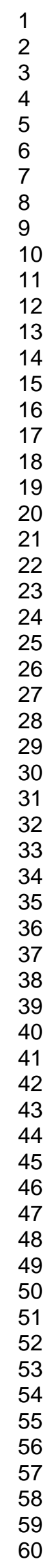
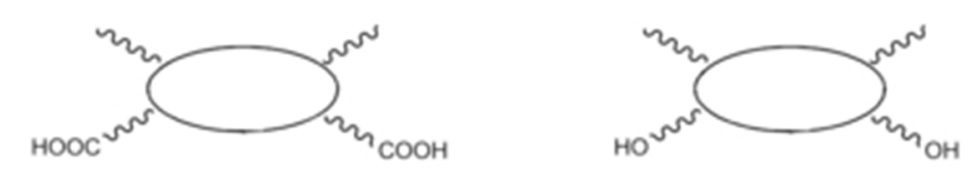

$30 \times 22 \mathrm{~mm}(300 \times 300 \mathrm{DPI})$

URL: http://mc.manuscriptcentral.com/LMSC Email: polyreviews@bellsouth.net 


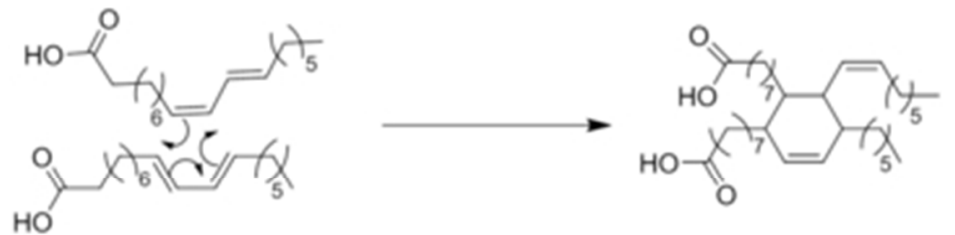




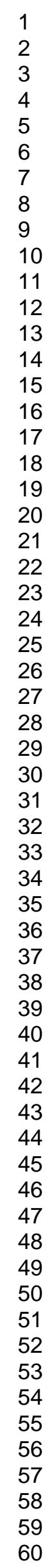

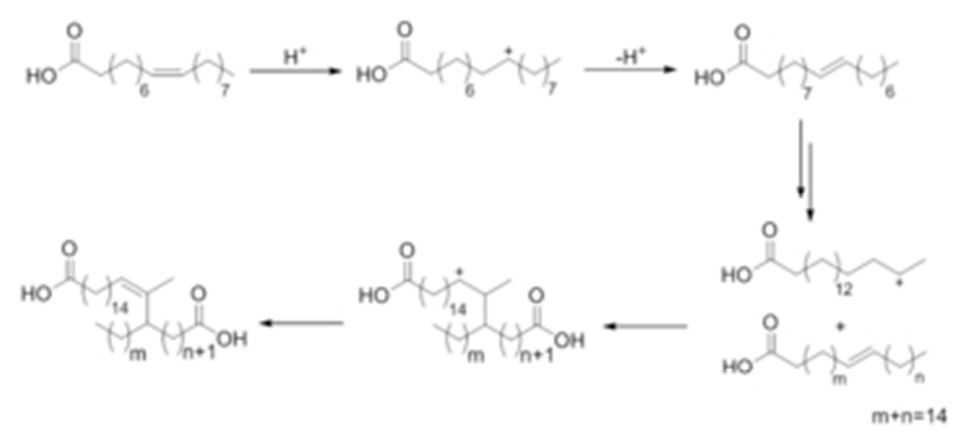

$30 \times 22 \mathrm{~mm}(300 \times 300 \mathrm{DPI})$

URL: http://mc.manuscriptcentral.com/LMSC Email: polyreviews@bellsouth.net 

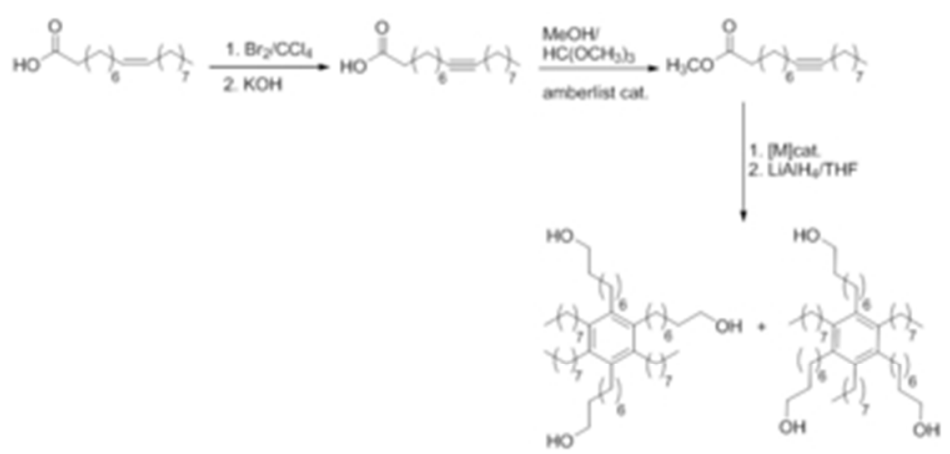

$30 \times 22 \mathrm{~mm}(300 \times 300$ DPI $)$

29

30

32

33

34

35

36

37

38

39

40

41

42

44

45

46

47

48

49

51

52

53

54

55

57

58

59

60

URL: http://mc.manuscriptcentral.com/LMSC Email: polyreviews@bellsouth.net 


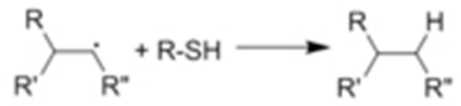

Ierminaison: R-S* + R-S* $\longrightarrow$ R-S.S-R

$30 \times 22 \mathrm{~mm}(300 \times 300 \mathrm{DPI})$

29

30

31

32

33

34

35

36

37

38

39

40

41

42

43

44

45

46

47

48

49

50

51

52

53

54

55

56

57

58

59

60

URL: http://mc.manuscriptcentral.com/LMSC Email: polyreviews@bellsouth.net 


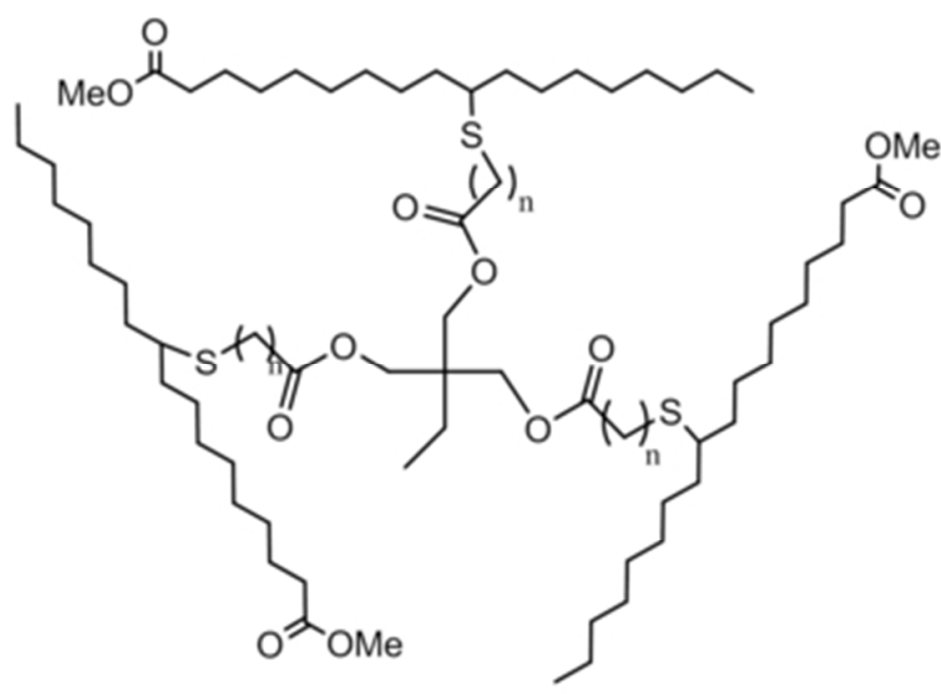

$30 \times 22 \mathrm{~mm}(300 \times 300 \mathrm{DPI})$ 


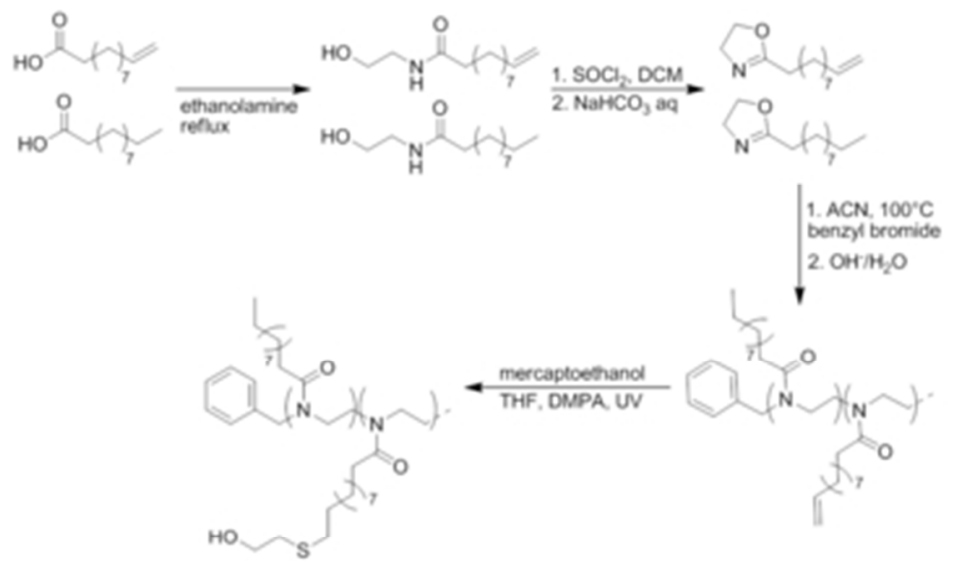

$30 \times 22 \mathrm{~mm}(300 \times 300$ DPI $)$ 

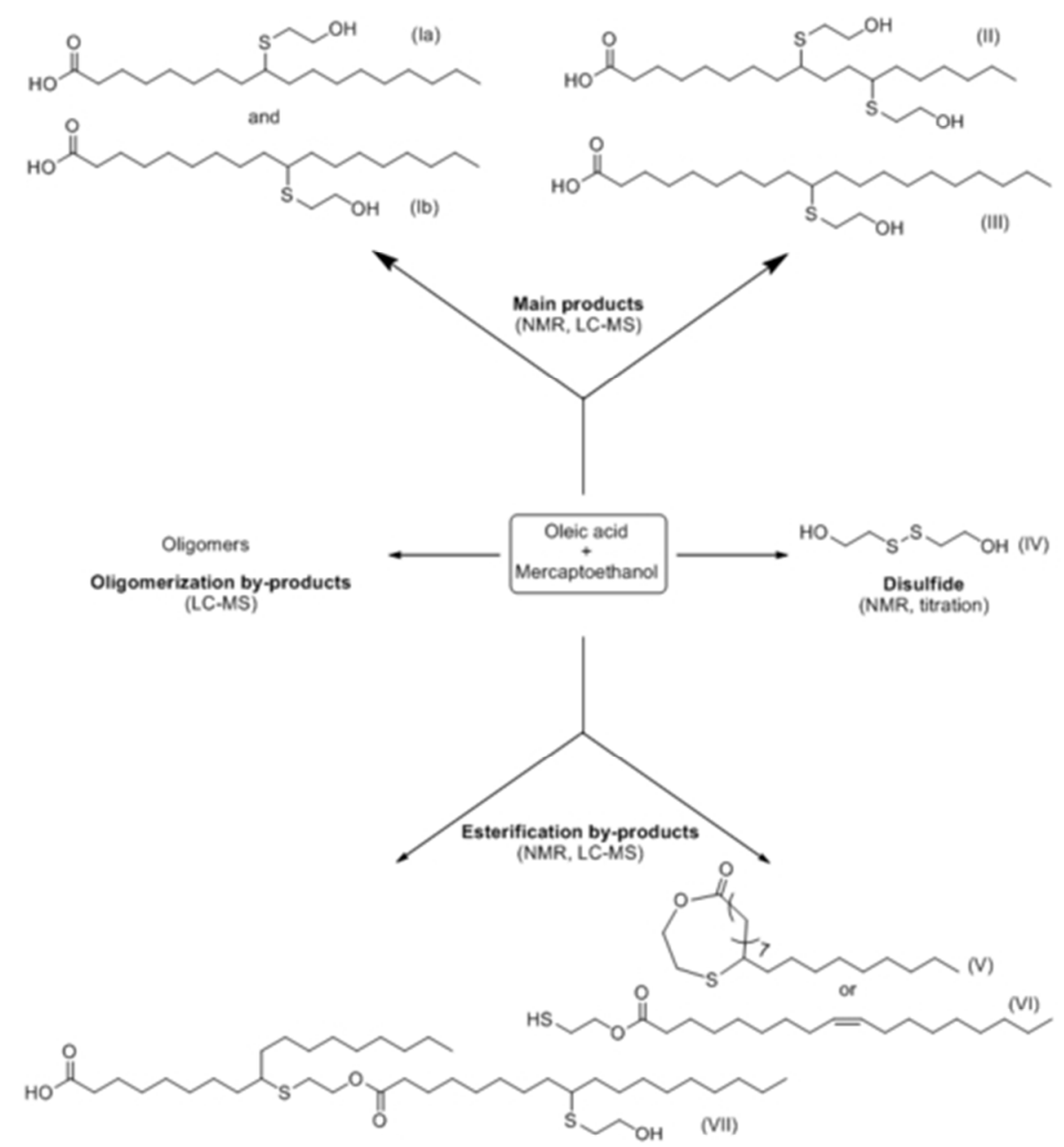

$40 \times 54 \mathrm{~mm}(300 \times 300$ DPI $)$ 
6

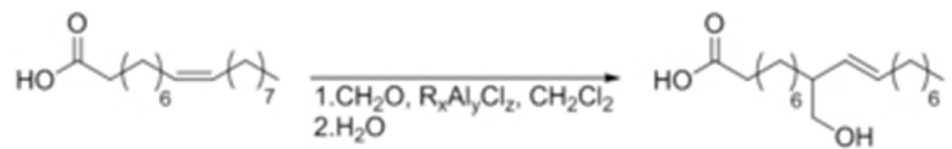


2

3

4

5

7

8

9

10

11

12

13

14

15

16

17

18

19

20

21

22

23

24

25

26

27

28

29

30

31

32

33

34

35

36

37

38

39

40

41

42

43

44

45

46

47

48

49

50

51

52

53

54

55

56

57

58

59

60
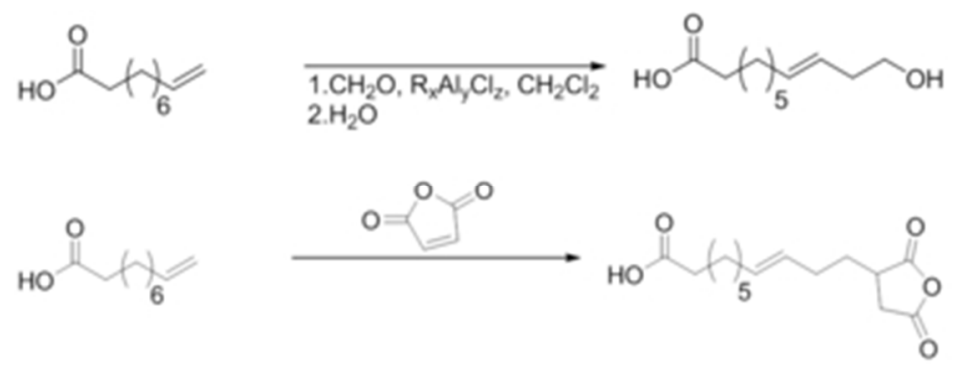

$30 \times 22 \mathrm{~mm}(300 \times 300$ DPI $)$

URL: http://mc.manuscriptcentral.com/LMSC Email: polyreviews@bellsouth.net 


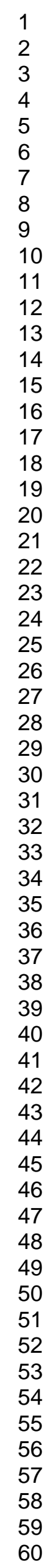

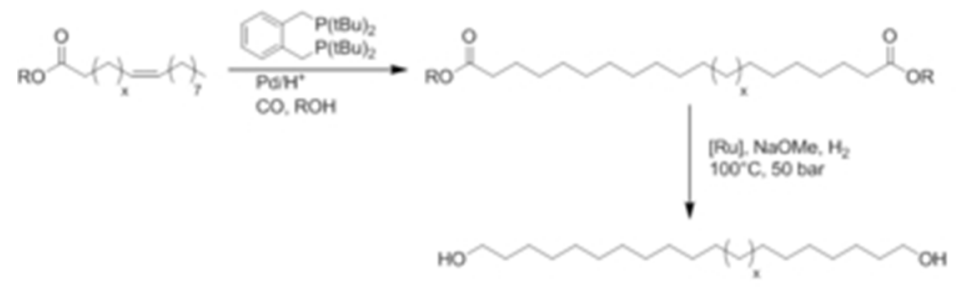

$30 \times 22 \mathrm{~mm}(300 \times 300 \mathrm{DPI})$

URL: http://mc.manuscriptcentral.com/LMSC Email: polyreviews@bellsouth.net 


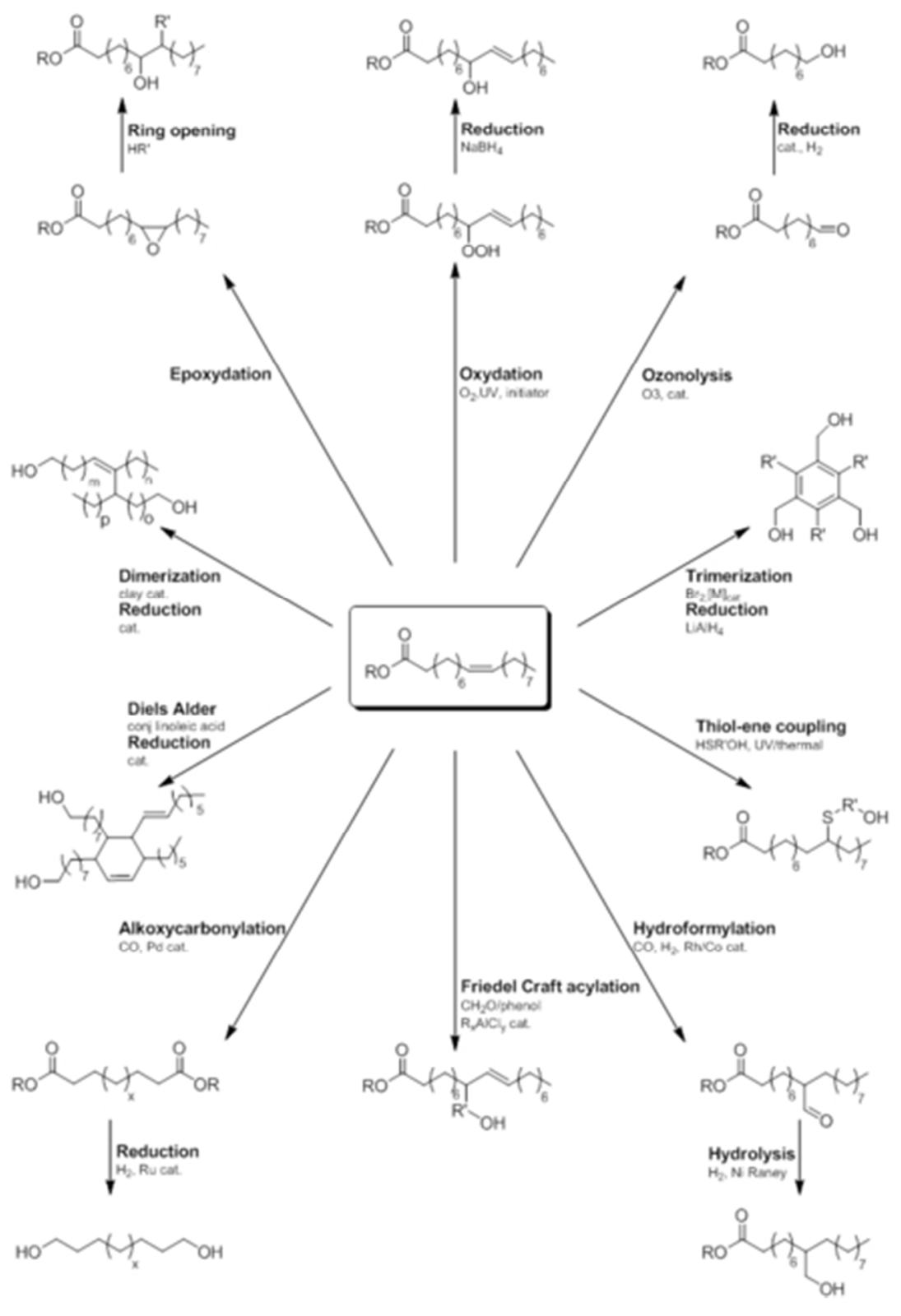

$40 \times 54 \mathrm{~mm}(300 \times 300 \mathrm{DPI})$ 


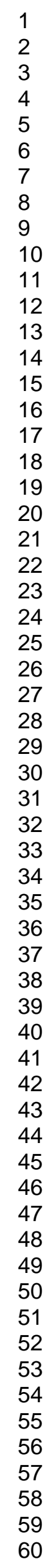

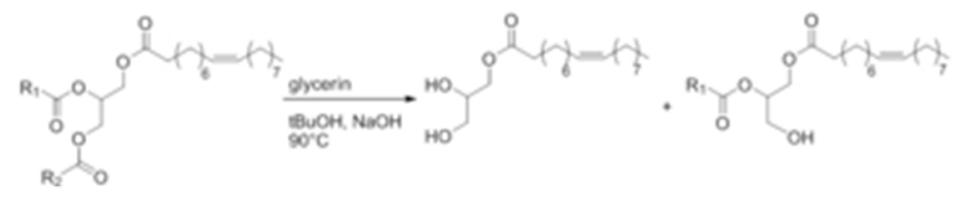

$30 \times 22 \mathrm{~mm}(300 \times 300 \mathrm{DPI})$

URL: http://mc.manuscriptcentral.com/LMSC Email: polyreviews@bellsouth.net 
2

4

5

6 


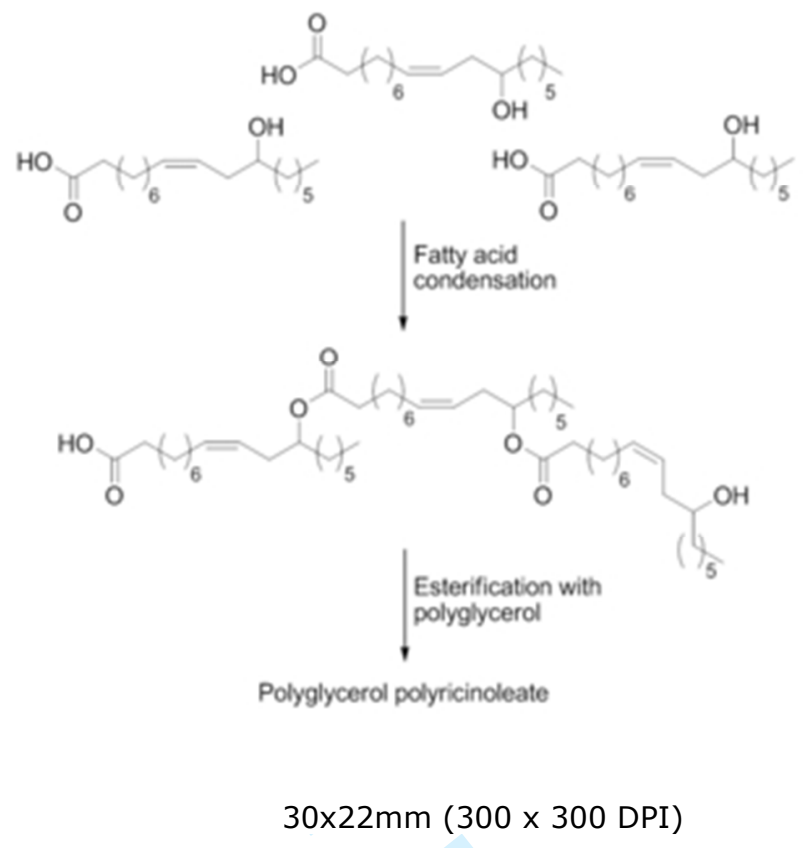

URL: http://mc.manuscriptcentral.com/LMSC Email: polyreviews@bellsouth.net 


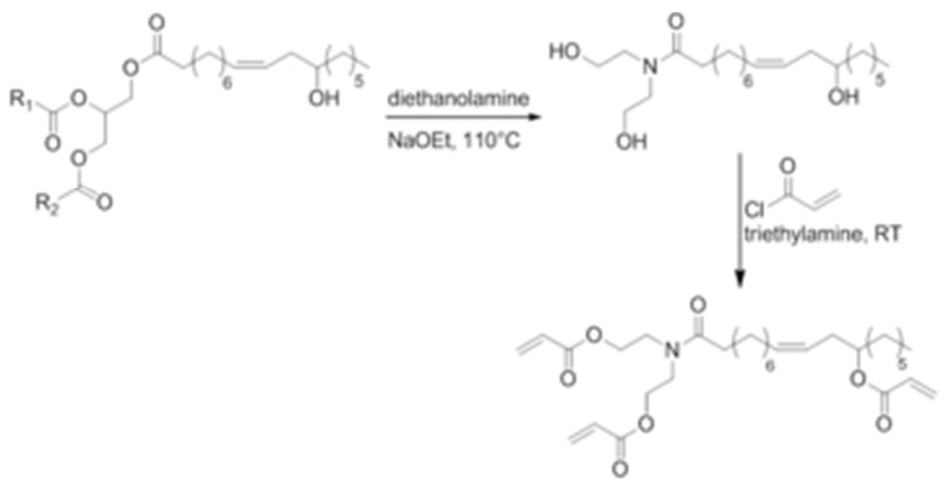

$30 \times 22 \mathrm{~mm}(300 \times 300 \mathrm{DPI})$

URL: http://mc.manuscriptcentral.com/LMSC Email: polyreviews@bellsouth.net 


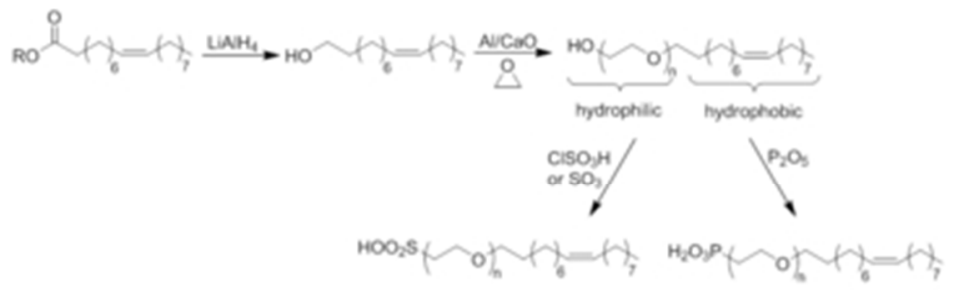

$30 \times 22 \mathrm{~mm}(300 \times 300 \mathrm{DPI})$

29

30

32

33

34

35

36

39

40

41

42

44

45

46

47

48

49

51

52

53

54

55

57

58

59

60

URL: http://mc.manuscriptcentral.com/LMSC Email: polyreviews@bellsouth.net 


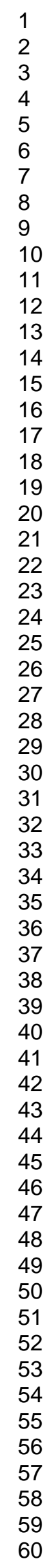

$30 \times 22 \mathrm{~mm}(300 \times 300 \mathrm{DPI})$

URL: http://mc.manuscriptcentral.com/LMSC Email: polyreviews@bellsouth.net 


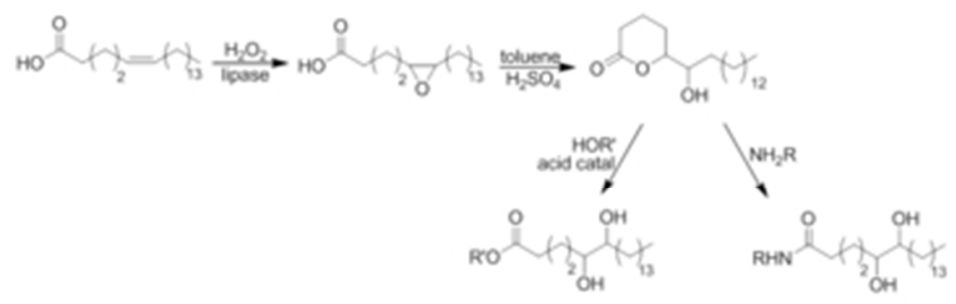

$30 \times 22 \mathrm{~mm}(300 \times 300 \mathrm{DPI})$

29

30

32

33

34

35

36

38

39

40

41

42

44

45

46

47

48

49

51

52

53

54

55

57

58

59

60

URL: http://mc.manuscriptcentral.com/LMSC Email: polyreviews@bellsouth.net 


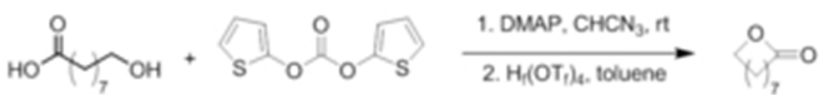

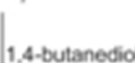

$\checkmark$

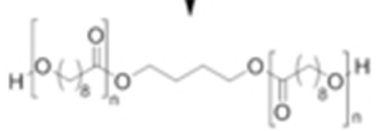




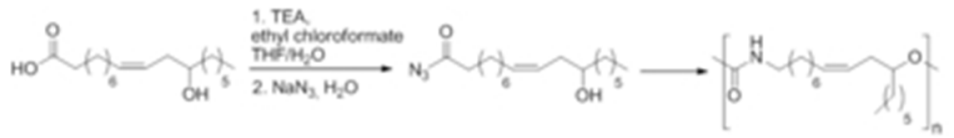

$30 \times 22 \mathrm{~mm}(300 \times 300$ DPI $)$

29

31

33

34

35

36

37

38

40

41

42

44

45

46

47

48

49

51

52

53

54

55

57

58

59

60

URL: http://mc.manuscriptcentral.com/LMSC Email: polyreviews@bellsouth.net 


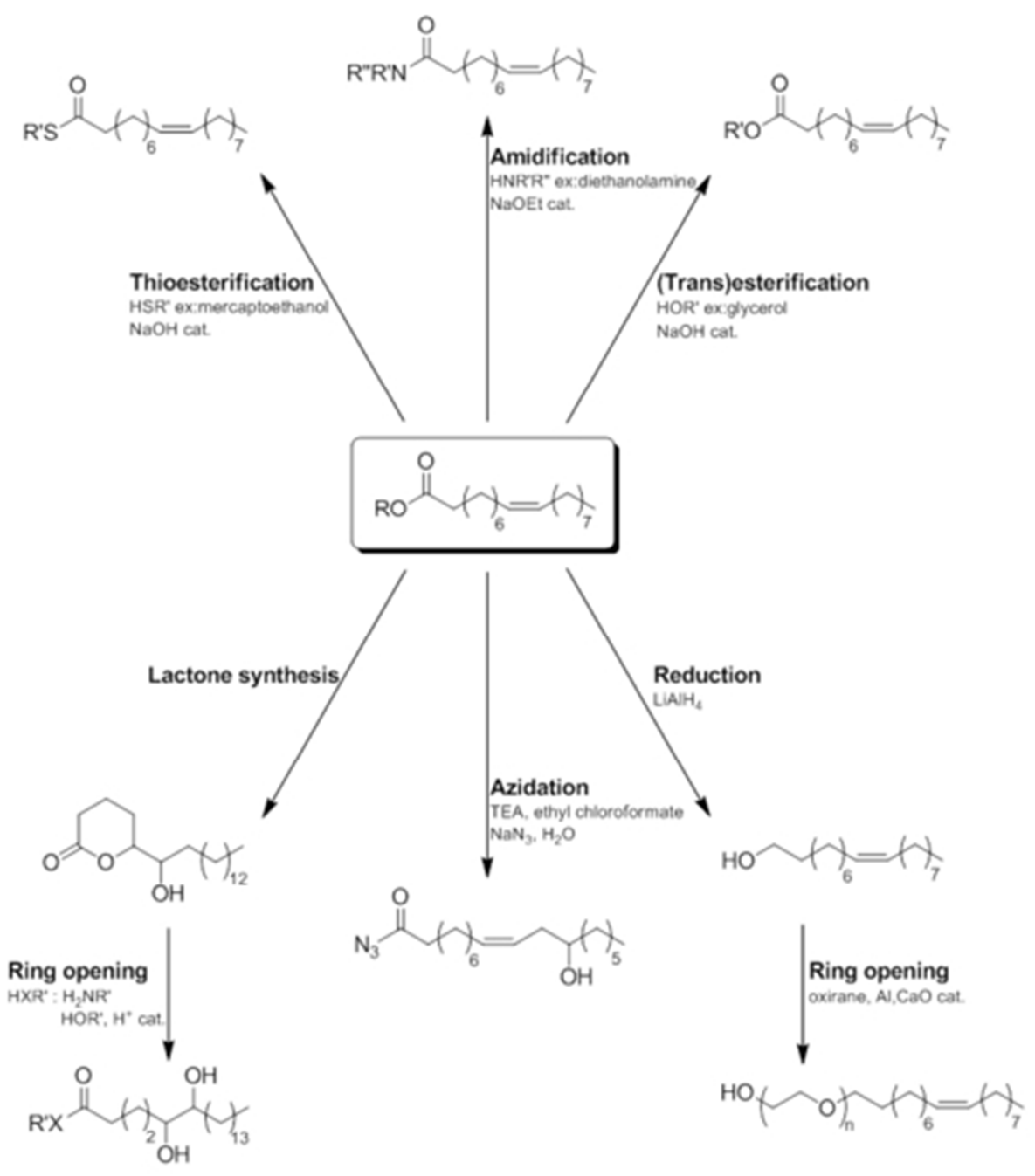

$40 \times 54 \mathrm{~mm}(300 \times 300 \mathrm{DPI})$ 
$\mathrm{HO} \widehat{\mathrm{OH}}$

1,3-propanediol

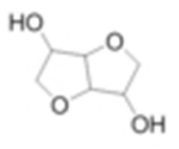

isosorbide

$30 \times 22 \mathrm{~mm}(300 \times 300 \mathrm{DPI})$

URL: http://mc.manuscriptcentral.com/LMSC Email: polyreviews@bellsouth.net 


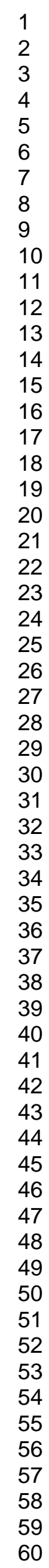

$30 \times 22 \mathrm{~mm}(300 \times 300 \mathrm{DPI})$

URL: http://mc.manuscriptcentral.com/LMSC Email: polyreviews@bellsouth.net 